Graphical Abstract
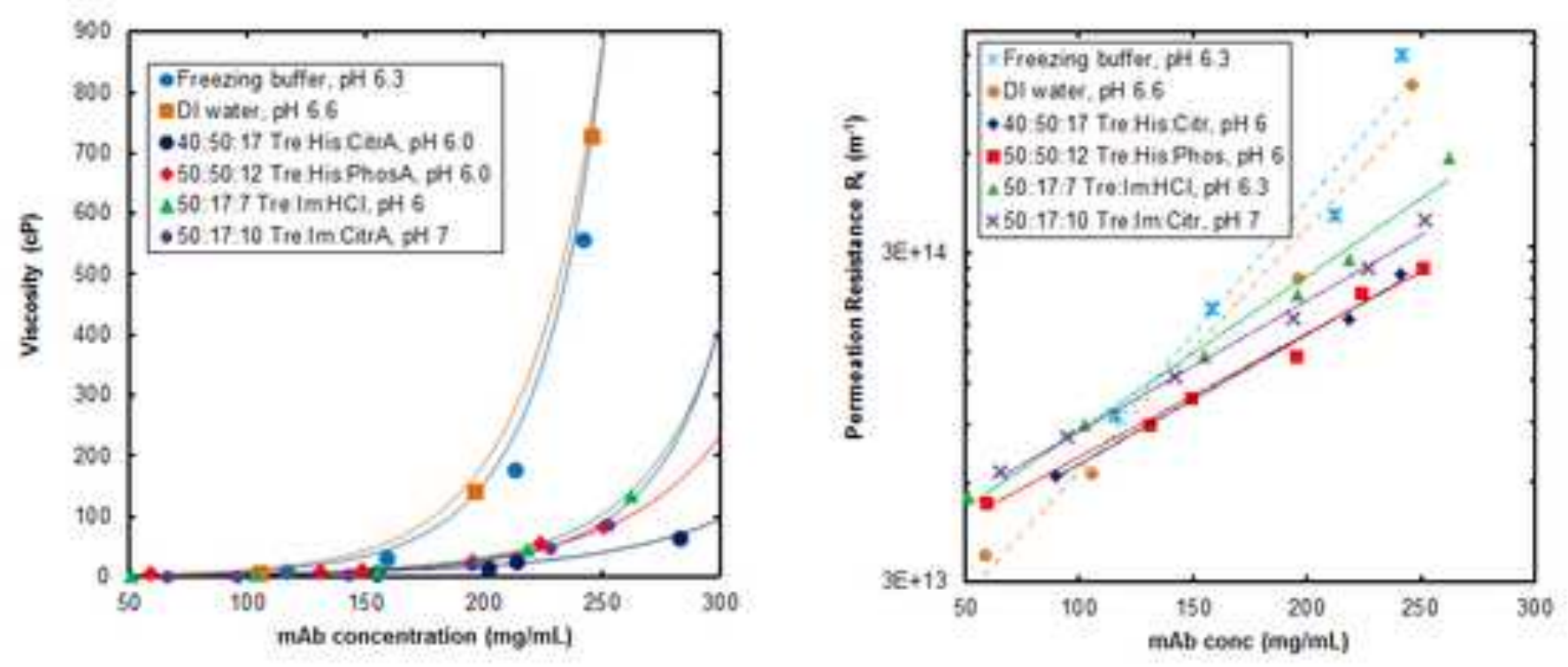

Signifitesnt decrease in flux

decline during tangential flow. ultrafiltration of an $\lg G 1$ mAb to $270 \mathrm{me} / \mathrm{mL}$ by the addition of high coneentrations of hiztidine or imidasole st co-solutes to lower the solution viscosity and enhance concentration

polarization-driven back-diffurion near the membrane walt

mAb concentration (mg/mL) 


\title{
High Concentration Tangential Flow Ultrafiltration of Stable Monoclonal Antibody Solutions with Low Viscosities
}

Jessica J. Hung, Ameya U. Borwankar, Barton J. Dear, Thomas M. Truskett and Keith P. Johnston

McKetta Department of Chemical Engineering, The University of Texas at Austin

\begin{abstract}
During production of concentrated monoclonal antibody formulations by tangential flow ultrafiltration (TFF), high viscosities and aggregation often cause extensive membrane fouling, flux decay and low product yields. To address these challenges, the co-solutes histidine or imidazole were added at high concentrations from 250 to $320 \mathrm{mM}$ to reduce the viscosity by up to ten-fold relative to conventional low co-solute formulations, to as low as $40 \mathrm{cP}$ at $250 \mathrm{mg} / \mathrm{mL}$. At high $\mathrm{mAb}$ concentrations of up to $280 \mathrm{mg} / \mathrm{mL}$, the transmembrane flux was increased threefold by adding high concentrations of co-solutes that also lowered the viscosity. Furthermore, the co-solutes also increased the mAb gel point concentration $c_{g}$ by up to 100 $\mathrm{mg} / \mathrm{mL} \mathrm{mAb}$ and thus enhanced concentration polarization-driven back-diffusion of the mAb at the membrane wall, which led to increased fluxes. The low viscosity and hollow fiber filter modules with straight flow paths enabled more uniform TMP and wall shear stress $\tau_{w}$ profiles, which mitigated the reversible flux decay that results from an axial decline in the local TMP. The concentrated $\mathrm{mAb}$ was stable by SEC before and after extended storage at $4^{\circ} \mathrm{C}$ and $37^{\circ} \mathrm{C}$.
\end{abstract}

Keywords: tangential flow ultrafiltration, concentration polarization, viscosity, high concentration, monoclonal antibody

\section{INTRODUCTION}

For subcutaneous (subQ) delivery of monoclonal antibodies (mAb) and other protein therapeutics, the desired dosage often requires protein concentrations of $150 \mathrm{mg} / \mathrm{mL}$ or higher given the small injection volume of $1.5 \mathrm{~mL}$ [1]. At these concentrations, attractive short-ranged interactions between proteins may produce aggregation [2] and/or high viscosities [3, 4] above the desired limit of $20-50 \mathrm{cP}$ for subQ injection [5]. Even though tangential flow filtration (TFF) is used commonly for manufacturing concentrated proteins, relatively few publications

Abbreviations: Trehalose (Tre), histidine (His), imidazole (Im), arginine (Arg), citric acid (CitrA), phosphoric acid (PhosA), Centrifugation filtration (CF) 
have reported results for concentrations above $150 \mathrm{mg} / \mathrm{mL}$. Here, low fluxes in TFF and concentration polarization resulting from high viscosities $[3,4,6]$ may result in protein gelation, membrane fouling and protein aggregation [7]. Thus, novel concepts would be highly beneficial for weakening protein interactions to reduce viscosity and aggregation, both to improve TFF ultrafiltration and to advance subcutaneous injection at high concentrations.

Several studies of TFF have optimized the transmembrane pressure (TMP), cross-flow rates and shear stress to reach concentrations of 150 to $200 \mathrm{mg} / \mathrm{mL}[6,8-12]$. These studies have attempted to minimize protein aggregation during filtration $[6,8,13]$ and to avoid large viscosity increases and the associated flux decay $[6,8,14-17]$ and large axial pressure drops $\Delta P[3,12]$, both of which limit the maximum achievable mAb concentration. The large pressure drops may exceed pump capacity $[3,4]$ and increase axial variation in TMP, with undesirably high TMP values at the influent port $[12,15,16]$ and back-filtration near the effluent port where the TMP is negative [12]. The TMP is typically optimized based on the transition point between the pressure-dependent and pressure-independent regions of the flux-TMP profile, which is also known as the 'knee-point TMP.' To maximize the membrane flux while minimizing the risk of protein gelation, the TMP should be maintained near this optimal value [6]. As protein concentration increases, it was found that the optimal TMP decreases [6]. The low optimal TMP is problematic since high TMPs would be desirable to overcome losses in protein fluxes at high concentrations resulting from concentration polarization and fouling. In an alternative approach, single-pass TFF has been used to reach a final $\mathrm{mAb}$ concentration of $225 \mathrm{mg} / \mathrm{mL}$ by eliminating the recirculation loop to minimize mAb exposure to high shear stresses in the pump head [13].

In TFF, fouling and concentration polarization may be mitigated by applying an appropriate wall shear stress $\tau_{w}$ or shear rate $\gamma_{w}$ to sweep protein molecules near the wall back into the bulk flow $[14,18]$. If the shear stress is too large, it may cause protein denaturation and aggregation [19], especially in the presence of air-solution and solution-solid interfaces [20, 21]. For proteins, flat sheet cassettes (filter modules) are typically used for TFF due to facile scalability and high fluxes [6, 8-10, 13, 22, 23]. However, given the serpentine flow path, a high local $\tau_{w}$ is required in the stagnation zones in the 90-degree bends to mitigate protein fouling and concentration polarization, but this may cause protein denaturation and aggregation. For example, an average $\tau_{w}$ of $200-300 \mathrm{~Pa}$ is recommended for ultrafiltration of concentrated $\mathrm{mAb}$ 
solutions at typical feed flow rates of $300-400 \mathrm{LMH}$ (liters per square meter per hour) with the flat sheet geometry $[6,8]$. In contrast, more uniform flow in the hollow fiber geometry may avoid the possibility of high local values of $\tau_{w}$ to minimize shear-induced protein aggregation, particularly at high concentrations. Recent advancement in the design of asymmetric hollow fiber membranes make them more attractive for protein separations given improved fluxes [14, 24].

The design of mAb formulations with lower viscosities at high concentrations would be highly beneficial for advancing ultrafiltration in TFF. In TFF, lower viscosities would enable higher fluxes, lower axial $\Delta P$, and better control of the TMP for lower values of $\tau_{w}$. The solution viscosity exhibits an exponential dependence on the mAb concentration, as described by the Ross-Minton equation [4, 25] (Eq. 1),

$$
\eta=\eta_{0} \exp \left(\frac{c[\eta]}{1-\frac{k}{v} c[\eta]}\right)
$$

where $\eta$ is the solution viscosity, $\eta_{0}$ is the solvent viscosity, $c$ is the mAb concentration, $[\eta]$ is the intrinsic viscosity, $k$ is the crowding factor and $v$ is the Simha shape factor. To first order, the intrinsic viscosity $[\eta]$ is an effective specific volume of the mAb molecule at infinite dilution [4, 26], whereby the viscosity increases with $[\eta]$. Furthermore, the effect of pair-wise interparticle interactions on $\eta$ may be captured by $[\eta]$, as described in a virial expansion of viscosity as a function of mAb concentration [4]. The level of the exponential increase in viscosity may be ameliorated by weakening attractive intermolecular interactions at higher concentrations to lower $[\eta]$. Even when protein-protein interactions are repulsive at dilute conditions, they may become attractive at high concentrations $[2,4]$ due to anisotropic short-ranged electrostatic and hydrophobic interactions [27] at small protein separation distances $<5 \mathrm{~nm}$ [28]. The anisotropic nature of these interactions arises from the heterogeneous distribution of charged and hydrophobic residues on the protein surface [29-31].

Recently, strategies to lower the solution viscosity and improve mAb stability by the addition of high concentrations $(150-1000 \mathrm{mM})$ of co-solutes are gaining attention. In some cases, electrostatic interactions can be modulated by the addition of salts to screen the protein charge and minimize attractive local anisotropic interactions [4, 11, 32-35]. Furthermore, 
hydrophobic salts have been hypothesized to adsorb on hydrophobic sites and further screen hydrophobic interactions, resulting in large viscosity reductions [36, 37]. The amino acids arginine [5, 28, 38-43] and histidine [44] in the protonated form have been shown to produce significant viscosity reductions at high co-solute concentrations without adversely impacting the mAb stability. The two are hypothesized to screen both electrostatic and hydrophobic interactions via a similar binding mechanism [39, 45, 46]. Alternatively, we introduced a concept of adding a high concentration of a nonionic crowding agent, for example the disaccharide trehalose $[47,48]$ to provide a depletion attraction force $[49,50]$ to osmotically compress proteins to attempt to raise the stability. According to a free energy model, the compression generates nanoclusters of primary colloidal charged spheres, whereby the protein may adopt a more stable conformation through a self-crowding mechanism [51,52]. Despite the benefits of co-solutes on protein viscosity and stability, to our knowledge, protein solutions with elevated concentrations of co-solutes have not been formed by TFF.

Herein we utilize high concentrations of histidine or imidazole with trehalose as cosolutes to form stable solutions of a human IgG1 mAb by TFF with viscosities as low as 70 and $40 \mathrm{cP}$ at 280 and $255 \mathrm{mg} / \mathrm{mL}$, respectively. Histidine at low concentrations is a common pharmaceutical buffer that may preferentially bind to and shield interaction-prone mAb residues to mitigate protein network formation (reversible aggregates) and possibly reduce the viscosity significantly. In control experiments with low co-solute concentrations, the solutions gelled and were $\sim 10$ times more viscous than the formulations with high concentrations of co-solute, resulting in poor transmembrane fluxes. The low viscosities of the solutions and the choice of the hollow fiber geometry are shown to provide for low axial $\Delta P$, resulting in a relatively uniform and small wall shear stress and more uniform TMP. The high concentrations of co-solute also enhance concentration polarization-driven back-diffusion of the mAb near the membrane wall at high $\mathrm{mAb}$ concentration by increasing the $\mathrm{mAb}$ gel point concentration $c_{g}$. Because these factors mitigate flux decay from stagnation at the membrane wall and from axial decline in the local TMP, it became possible to achieve relatively low losses in membrane flux (low permeation resistance). A secondary objective was to show that the TFF process is well suited for forming concentrated protein solutions with high co-solute levels and low viscosities to complement previous techniques $[11,36,37,41-43,47,48]$. The mAb solutions were diluted and studied by 
SEC before and after extended storage at $4^{\circ} \mathrm{C}$ to show that the formation of irreversible aggregates was minimal.

\section{MATERIALS AND METHODS}

\subsection{Materials}

The IgG1 mAb used in this study was provided by AbbVie as a concentrated solution at 130 $\mathrm{mg} / \mathrm{mL}$ in a proprietary buffer containing $10 \mathrm{mM}$ histidine, $4 \%$ mannitol and $0.1 \%$ Tween-80 at pH 5.8 (referred to as the "freezing buffer"). The mAb solution was aliquoted into $5 \mathrm{ml}$ subsamples into 5-mL cryogenic vials (Corning Incorporated, Corning, NY) and frozen using a dry ice-ethanol freezing mixture for extended storage at $-80^{\circ} \mathrm{C} . \alpha$-trehalose dihydrate (Tre) was purchased from Ferro Pfanstiehl Laboratories Inc., Waukegan, IL. All other chemicals (Lhistidine (His), imidazole (Im), citric acid monohydrate (CitrA), hydrochloric acid (HCl), ophosphoric acid (PhosA)) were purchased from Thermo Fisher Scientific, Fair Lawn, NJ. Disposable $0.22 \mu \mathrm{m}$ polyethersulfone (PES) bottle top and $13 \mathrm{~mm}$ syringe sterile filters were obtained from Celltreat Scientific Products, Shirley, MA (product codes 229717 and 229746). Disposable $50 \mathrm{kDa}$ PES MidiKros hollow fiber filter modules with a length of $20 \mathrm{~cm}$ and an ID of $0.5 \mathrm{~mm}$ (36 fibers and $115 \mathrm{~cm}^{2}$ area, part no. D02-E050-05-N) or $1.0 \mathrm{~mm}$ (12 fibers and 75 $\mathrm{cm}^{2}$ area, part no. D02-E050-10-N from Spectrum Labs, Rancho Dominguez, CA) were utilized for TFF. Amicon Ultra-15 Ultracel - 30K centrifugal filters were purchased from Merck Millipore Ltd. Ireland.

\subsection{Diafiltration and ultrafiltration to $250 \mathrm{mg} / \mathrm{mL}$ by $\mathrm{TFF}$}

Buffers were prepared at the desired co-solute composition and sterile filtered with the Celltreat bottle top PES filters and then degassed under vacuum for 30 minutes. The frozen mAb stock ( $25 \mathrm{~mL}$ in 5 vials) was thawed in a $4{ }^{\circ} \mathrm{C}$ water bath and diluted with an equal volume (25 $\mathrm{mL}$ ) of the buffer, resulting in a mAb concentration of $65 \mathrm{mg} / \mathrm{mL}$. The diluted $\mathrm{mAb}$ solution was gently mixed in a 50-mL centrifuge tube, which served as the retentate reservoir during the TFF experiments. In two of the experiments, the buffer exchange was done at a lower concentration of $20 \mathrm{mg} / \mathrm{mL}$ to attempt to form less turbid solutions. In one of these experiments, the diluted $\mathrm{mAb}$ solution was additionally sterile-filtered using the $0.22 \mu \mathrm{m}$ bottle top filters and degassed prior to buffer exchange. 
The diluted mAb solution was buffer-exchanged at constant concentration with permeation of six diavolumes $(150 \mathrm{~mL})$ of the desired formulation buffer with a KrosFlo Research II TFF system (Spectrum Labs, Rancho Dominguez, CA) operated in a constantvolume mode. A schematic of the TFF setup is given in Fig. S1. The TMP was maintained at 0.80 bar using a KrosFlo automatic backpressure valve (Spectrum Labs, Rancho Dominguez, CA), which regulated the pressure by constricting the retentate line. The feed cross-flow rate was set at $100 \mathrm{~mL} / \mathrm{min}$ for the $1.0 \mathrm{~mm}$ ID filter module and $220 \mathrm{~mL} / \mathrm{min}$ for the $0.5 \mathrm{~mm}$ ID filter module, corresponding to calculated wall shear rates inside each fiber of 1415 and $8300 \mathrm{~s}^{-1}$ respectively. The retentate reservoir was gently mixed throughout the process using a Vari Mix Platform Rocker (Thermo Fisher Scientific, Fair Lawn, NJ) set at the maximum speed and rocking angle along with periodic hand swirling. The buffer-exchanged solution was recovered and sterile filtered, then stored overnight at $4^{\circ} \mathrm{C}$, after which it was concentrated to $\sim 250 \mathrm{mg} / \mathrm{mL}$ the following day using the $1.0 \mathrm{~mm}$ ID filter module.

When the $1.0 \mathrm{~mm}$ ID filter module was used during diafiltration, the filter membrane was cleaned between diafiltration and ultrafiltration to recover membrane performance. When the 0.5 mm module was used for the diafiltration step, the corresponding ultrafiltration was performed with a new $1.0 \mathrm{~mm}$ ID module. The new filters were first flushed with $200 \mathrm{~mL}$ of DI water without recirculating or permeating any material in order to flush out residual glycerin impurities. Both the new and used membranes were then cleaned prior to filtration by permeating $4 \mathrm{~mL}$ DI water $/ \mathrm{cm}^{2}$ membrane area, circulating $0.5 \mathrm{~N} \mathrm{NaOH}$ for 30 minutes to decompose adsorbed protein, followed by permeating another $4 \mathrm{~mL}$ DI water $/ \mathrm{cm}^{2} \mathrm{membrane}$ area to flush the residual $\mathrm{NaOH}$ and degraded protein out of the membrane pores. A normalized water permeability (NWP) test was then conducted to check the performance of the regenerated membrane prior to ultrafiltration. The NWP was also determined for the fouled membrane after both diafiltration and ultrafiltration.

The buffer-exchanged mAb solution was concentrated from $65 \mathrm{mg} / \mathrm{mL}$ to $250 \mathrm{mg} / \mathrm{mL}$ by ultrafiltration using the $1.0 \mathrm{~mm}$ ID hollow fiber module. The feed cross-flow rate was initially kept at $100 \mathrm{~mL} / \mathrm{min}$ (corresponding to a cross-flow flux of $800 \mathrm{LMH}$ ) and the TMP was maintained at 0.80 bar. When the mAb solution became too viscous $(>150 \mathrm{cP}$, the TMP could no longer be regulated. At this point, the TMP was maintained at 0.80 bar by partially restricting 
the permeate line (to increase the permeate back-pressure) and decreasing the feed cross-flow rate (to decrease $\Delta P$ across the filter module). The retentate was kept well-mixed using the rocker set at the maximum speed. The rocker angle for the Vari Mix Platform Rocker was gradually reduced over time as the fluid level in the retentate reservoir decreased in order to keep the feed and retentate return lines submerged. The retentate concentration at any given time was estimated based on the permeate mass, which was monitored in real time, assuming no permeation of mAb through the membrane, and was subsequently verified by UV-Vis spectroscopy via $150 \mu \mathrm{L}$ aliquots. The instantaneous flux was also determined by the change in permeate mass in one-minute intervals. The final $250 \mathrm{mg} / \mathrm{mL}$ solution was recovered and mixed by gentle pipetting to homogenize the solution prior to characterization by DLS, UV-Vis spectroscopy and syringe capillary viscometry.

Low co-solute controls were also prepared by centrifugation filtration, as described in the Supporting Information (Section 6.1), to place the results from TFF in perspective.

\subsection{TFF membrane fouling characterization}

The extent of membrane fouling at the end of ultrafiltration was assessed by measuring the percent reduction in the normalized water permeability (NWP). The DI water flux of the cleaned membrane was measured at room temperature $\left(20^{\circ} \mathrm{C}\right)$ and a TMP of $0.25 \mathrm{bar}, 0.50 \mathrm{bar}$ and 0.8 bar before the start of ultrafiltration. The pre-ultrafiltration NWP in LMH (liters per square meter membrane area) per bar of applied TMP was calculated from the slope of the water flux vs TMP curve. The NWP of the fouled membrane after ultrafiltration was measured in the same way after the membrane was first washed by recirculating $200 \mathrm{~mL}$ DI at a cross-flow flux of $800 \mathrm{LMH}$ for 10 minutes to recover reversibly adsorbed protein.

\section{$2.4 m A b$ concentration determination and turbidity by $U V$-Vis spectroscopy}

The $\mathrm{mAb}$ concentration in the intermediate and final solutions was measured in duplicate at 500x dilution using a Cary $60 \mathrm{UV}-\mathrm{V}$ is spectrophotometer (Agilent Technologies, Santa Clara, $\mathrm{CA}$ ). The concentrated mAb solution was diluted in $50 \mathrm{mM} \mathrm{pH} 6.4$ sodium phosphate buffer, and the absorbance at $280 \mathrm{~nm}$ was measured in a QS quartz cuvette (Hellma GmbH and Co, Mullheim, Germany) with a path length of $1 \mathrm{~cm}$. The absorbance was converted to a mass concentration via the Beer-Lambert law using the provided mAb extinction coefficient of 1.42 
$\mathrm{mL} / \mathrm{mg} / \mathrm{cm}$. The turbidity of the buffer-exchanged $20 \mathrm{mg} / \mathrm{mL} \mathrm{mAb}$ stock as well as of the concentrated mAb solution was measured undiluted using a Cary $60 \mathrm{UV}$-Vis spectrophotometer (Agilent Technologies, Santa Clara, CA) as described in the Supporting Information (Section $6.2)$.

\subsection{Syringe capillary viscometry}

The viscosity of the mAb solution was measured at room temperature in triplicate using a custom syringe capillary viscometer as described previously [47]. Briefly, a 25G (ID =0.1 mm; $\mathrm{L}=1.5$ ") Precision Glide needle (Becton Dickinson \& Co.) was attached to a $1.0 \mathrm{~mL}$ LuerLok $^{\mathrm{TM}}$ syringe (Becton Dickinson \& Co.). A $100-125 \mu \mathrm{L}$ aliquot of the solution was placed in a $0.1 \mathrm{~mL}$ conical vial (catalog no. 03-341-15; Wheaton, Millville, NJ). The solution was warmed to $25^{\circ} \mathrm{C}$ with a heating block (Thermo Scientific, Waltham, MA) and drawn into the syringe, and the flow rate of the solution through the needle was determined by ImageJ image analysis [53] of a video taken with a Kodak Z812 IS zoom digital camera. The change in the solution column height was tracked over time and correlated to the sample volume based on an established calibration curve, as described in the Supporting Information (Section 6.4.1). The flow rate was correlated to a viscosity based on the Hagen-Poiseuille equation, using a calibration curve determined from a set of viscosity standard solutions (Section 6.4.2). The viscosities measured at high concentration by the capillary viscometer correspond to an estimated shear rate of 25 - 500 $\mathrm{s}^{-1}$, as demonstrated in the Supporting Information (Section 6.4.3), assuming a Newtonian shear response to fluid flow ( $\mathrm{n}=1$ power-law dependence between viscosity and shear rate) [54].

\subsection{Size exclusion chromatography}

For characterization of soluble irreversible aggregate levels in the final solutions, the $\mathrm{mAb}$ solution was diluted to $2 \mathrm{mg} / \mathrm{mL}$ in the mobile phase $\left(92 \mathrm{mM} \mathrm{NaHPO}, 211 \mathrm{mM} \mathrm{Na}_{2} \mathrm{SO}_{4}\right.$, $\mathrm{pH}$ 7). The standard solution was prepared by diluting freshly-thawed mAb monomer stock (as provided in the original freezing buffer at $130 \mathrm{mg} / \mathrm{mL}$ ) in the mobile phase. The diluted samples were sterile filtered through a $0.22 \mu \mathrm{m}$ PES syringe filter (Celltreat Scientific Products, Shirley, MA). Duplicate $10 \mu \mathrm{L}$ injections of each sample were analyzed with a Waters Breeze HPLC (Waters Corporation, Milford, MA) equipped with a Tosoh Biosciences TSKgel3000SW $\mathrm{XL}_{\mathrm{L}}$ column (Tosoh Corporation, Tokyo, Japan) and operated at a mobile phase flow rate of 0.5 $\mathrm{mL} / \mathrm{min}$. The eluate was monitored by the UV absorbance at $214 \mathrm{~nm}$ and $280 \mathrm{~nm}$. The soluble 
(small, irreversible) aggregate content was quantified by the percentage monomer as determined from the ratio of monomer and aggregate peak areas for the diluted samples. The insoluble (large, irreversible) aggregate content was quantified by the monomer recovery, which was determined from the ratio of the monomer peak areas for the dilute and concentrated solutions for the post-ultrafiltration samples, and for the pre and post-storage solutions for the storage stability tests.

\subsection{Sample storage stability study}

Small $150 \mu \mathrm{L}$ aliquots of the final mAb solution were stored in capped $0.1 \mathrm{~mL}$ conical vials (Wheaton, Millville, NJ) sealed with Parafilm. The sealed vials were stored in a $-40^{\circ} \mathrm{C}$ freezer, in a refrigerator at $4{ }^{\circ} \mathrm{C}$ and in a water bath at $37^{\circ} \mathrm{C}$ for up to 8 weeks. To minimize evaporative losses, the samples stored at $37^{\circ} \mathrm{C}$ were additionally sealed with three additional alternating layers of aluminum foil and Parafilm. Individual aliquots were removed from storage at 4 days, 1 week, 2 weeks, 4 weeks and 8 weeks and characterized by UV-Vis spectroscopy, syringe capillary viscometry and DLS measurements at a scattering angle of $90^{\circ}$. The samples were discarded after characterization, so that a fresh aliquot was used for each time point.

\section{RESULTS AND DISCUSSION}

\subsection{Addition of high concentrations of co-solute reduces solution viscosity at $250 \mathrm{mg} / \mathrm{mL} \mathrm{mAb}$}

We begin by describing control experiments with low co-solute concentrations. As seen in Table 1, these solutions formed by centrifugation filtration (CF) buffered with $10 \mathrm{mM}$ His (freezing buffer) or $30 \mathrm{mM}$ His were extremely viscous, exceeding $200 \mathrm{cP}$ at $240 \mathrm{mg} / \mathrm{mL}$ and $400 \mathrm{cP}$ at $270 \mathrm{mg} / \mathrm{mL}$. These low co-solute controls had a large inherent viscosity

$$
\eta_{\text {inh }}=\frac{\ln \left(\frac{\eta}{\eta_{0}}\right)}{c}
$$

of $\sim 22 \mathrm{~mL} / \mathrm{g}$. To some extent, $\eta_{\text {inh }}$ normalizes the solution viscosity $\eta$ for the $\mathrm{mAb}$ concentration $c$ and solvent viscosity $\eta_{0}[55]$. The inherent viscosity qualitatively reflects the strength of attractive interactions that raise the viscosity in a similar manner as for [ $\eta$. The addition of 150 $\mathrm{mM} \mathrm{NaCl}$ lowered $\eta_{\text {inh }}$ to $18.0 \mathrm{~mL} / \mathrm{g}$, likely indicating a weakening of attractive interactions by electrostatic screening, as observed for certain mAbs previously $[4,11,32]$. The same low co- 
solute solution in the freezing buffer was significantly more viscous when manufactured by TFF (Table 2), as will be explained below, increasing to $550 \mathrm{cP}$ with a $\eta_{\text {inh }}$ of $26 \mathrm{~mL} / \mathrm{g}$ at $240 \mathrm{mg} / \mathrm{mL}$ $\mathrm{mAb}$. Similarly high viscosities were obtained for a co-solute-free control mAb solution in DI water (Table 2, Fig. 1).

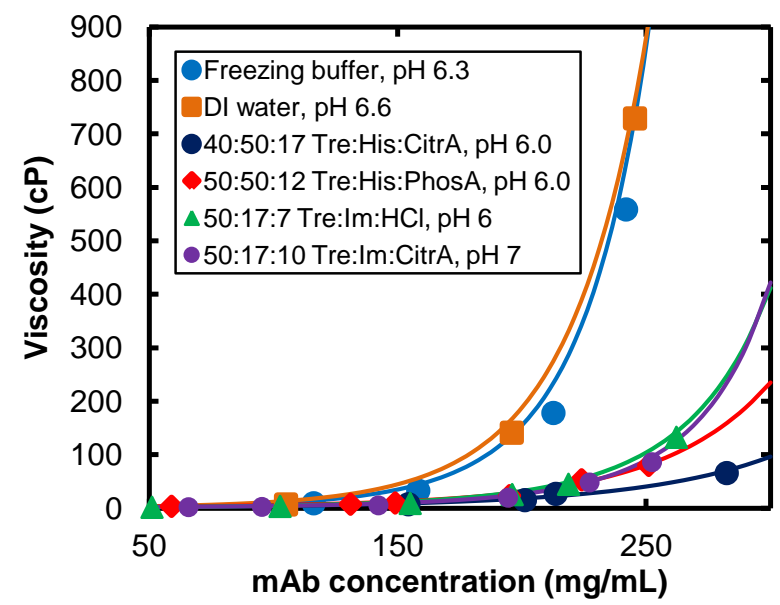

(a)

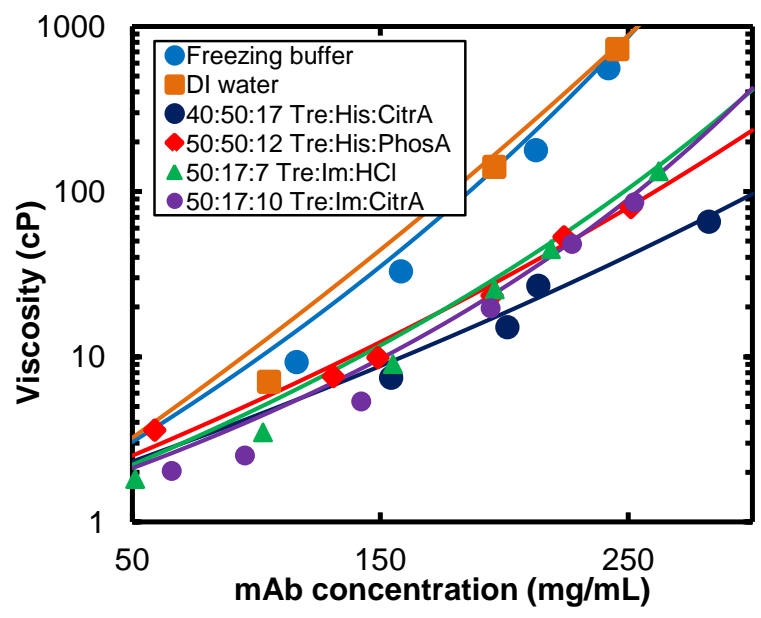

(b)

Figure 1. mAb solution viscosities during ultrafiltration to $250 \mathrm{mg} / \mathrm{mL} \mathrm{mAb}$ by TFF plotted on a (a) linear and (b) log scale. The numbers in the formulation names represent concentration of each excipient in $\mathrm{mg} / \mathrm{mL}$. The solid lines represent two-parameter fits to the data by the Ross-Minton equation.

We now show that the addition of high concentrations of histidine $(50 \mathrm{mg} / \mathrm{mL}=320$ $\mathrm{mM}$ ) combined with trehalose ( 40 to $50 \mathrm{mg} / \mathrm{mL}=105-130 \mathrm{mM}$ ) to the $\mathrm{mAb}$ solution resulted in a large reduction of the solution viscosity $(\eta)$, particularly at the highest mAb concentrations. Remarkably, the high co-solute solutions manufactured by TFF were significantly less viscous than the low co-solute controls made by both TFF and CF. The high co-solute solutions remained below $50 \mathrm{cP}$ with phosphoric acid (PhosA) up to $220 \mathrm{mg} / \mathrm{mL}$ and with citric acid (CitrA) all the way to $\sim 260 \mathrm{mg} / \mathrm{mL}$, corresponding to $\eta_{i n h}$ of 17.0 and $14.5 \mathrm{~mL} / \mathrm{g}$ respectively (Fig. 1a, Table 2). On a semi-log plot (Fig. 1b), the slope of the viscosity profile gives a qualitative measure of $[\eta]$ of the mAb in the given buffer, as described by the Ross-Minton model in Eq. 1. The noticeably smaller slope for the high co-solute solutions (Fig. 1b) and two-parameter fits of the viscosity profiles to the Ross-Minton model (Fig. S2) both indicated a significant reduction in $\eta_{\text {inh }}$ and $[\eta]$ by the addition of high concentrations of co-solute (Table 2). Although the two formulations with high concentrations of His both resulted in low $\eta$ at $250 \mathrm{mg} / \mathrm{mL}$, the solution with CitrA as the counteracid was slightly less viscous, as shown in Fig. 1. Similarly low viscosities were also 
observed when a structurally-analogous base, imidazole (Im), was used instead of His as the crowding agent, as shown in Fig. 1 and Table 2.

To further investigate whether trehalose or histidine generated the significant viscosity reduction, additional centrifugation filtration experiments were performed at $\mathrm{pH} 6$ with high concentrations of either trehalose (Tre) alone or His-CitrA alone. The addition of $220 \mathrm{mM}$ Tre to the formulation buffered with $30 \mathrm{mM}$ His did not affect the mAb inherent viscosity, which was $22 \mathrm{~mL} / \mathrm{g}$ (Table 1, 3). In contrast, the solutions with 320:80 mM His:CitrA had significantly lower inherent viscosities of $14.5-15.5 \mathrm{~mL} / \mathrm{g}$ (Table 3), comparable to that of the Tre-His-CitrA solutions made by both CF (Table 3 ) and TFF (Table 2). Thus the large viscosity reductions observed by TFF in the high co-solute systems may be attributed to the His (and by extension, $\mathrm{Im})$ rather than Tre. Histidine's effect on mAb viscosity has also been seen in a study by Chen et al. [44], where up to $60 \mathrm{mM}$ His decreased the viscosity of an $\mathrm{IgG}_{2} \mathrm{mAb}$ by up to $2 \mathrm{x}$ at 150 $\mathrm{mg} / \mathrm{mL} \mathrm{mAb}$. However, although His and Im reduced the viscosity for the mAb's in Chen's study and ours, it does not mean that this effect may be generalized to other mAbs. Note that the large deviation in viscosity seen for the freezing buffer solutions prepared by TFF versus CF is not observed for the Tre-His-CitrA solution (Table 2, 3). It is likely that the low level of reproducibility for the freezing buffer solutions is caused by the ultrahigh viscosities at high mAb concentration, which results in significant pathway-dependent aggregation and gelation. In contrast, the much less viscous Tre-His-CitrA solutions that do not gel show better reproducibility between filtration techniques.

The marked reduction in $[\eta]$ and $\eta_{i n h}$ by addition of high concentrations of histidine and imidazole will now be shown to be consistent with a weakening of local attractive protein interactions. In the low co-solute (freezing buffer) and DI water formulations, the mAb exhibited an $[\eta]$ of 16 and $20 \mathrm{~mL} / \mathrm{g}$, respectively, with a sharp increase in viscosity with $\mathrm{mAb}$ concentration. The viscosity was similar to that of an 'ill-behaved' viscous $\mathrm{mAb}$ with strong local protein-protein interactions from a study by Liu et al., where a sharp deviation from the Ross-Minton model [4] was observed with an assumed [ $\eta$ ] of $6.3 \mathrm{~mL} / \mathrm{g}$. In contrast, the fits of the viscosity profiles of two 'well-behaved' non-viscous mAbs in the same study were excellent with this value of $[\eta]$. However, if both $[\eta]$ and $k / v$ were fit by non-linear regression, [ $]$ was found to be approximately $9 \mathrm{~mL} / \mathrm{g}$ for the well-behaved antibodies, while the ill-behaved 
antibody exhibited a large $[\eta]$ of $30 \mathrm{~mL} / \mathrm{g}$ [4], similar to our results in the low co-solute and DI formulations. The addition of high concentrations of His and $\mathrm{Im}$ reduced $[\eta]$ to $11-13 \mathrm{~mL} / \mathrm{g}$ (Table 2), more closely approaching the $[\eta]$ values of $8.4-8.6 \mathrm{~mL} / \mathrm{g}$ seen in earlier studies for a non-viscous human IgG antibody [56] and a a polyclonal antibody [26]. Polyclonal antibodies are known to exhibit weaker interactions and lower viscosities in some cases than monoclonal antibodies [11]. On the basis of these studies, the reduction of [ $\eta$ from $20 \mathrm{~mL} / \mathrm{g}$ to as low as 11 $\mathrm{mL} / \mathrm{g}$ in this study suggests that the addition of the co-solutes His/Im with Tre significantly weakened the attractive protein interactions. The viscosity behavior can be further characterized by the parameter $k / v$ (Table 2), which varied markedly between the low and high co-solute solutions, as discussed in the Supporting Information (Section 6.5).

A gradual increase in $\eta_{i n h}$ with concentration was also observed for all of the mAb solutions, as seen in Fig. S3. However, the $\eta_{\text {inh }}$ of the high co-solute solutions were consistently nearly two-fold lower than that of the low co-solute solutions at all mAb concentrations (Table 2, Fig. S3), likely indicating a significant reduction in attractive protein interactions by co-solute and $\mathrm{mAb}$ interactions, leading to the lower viscosities.

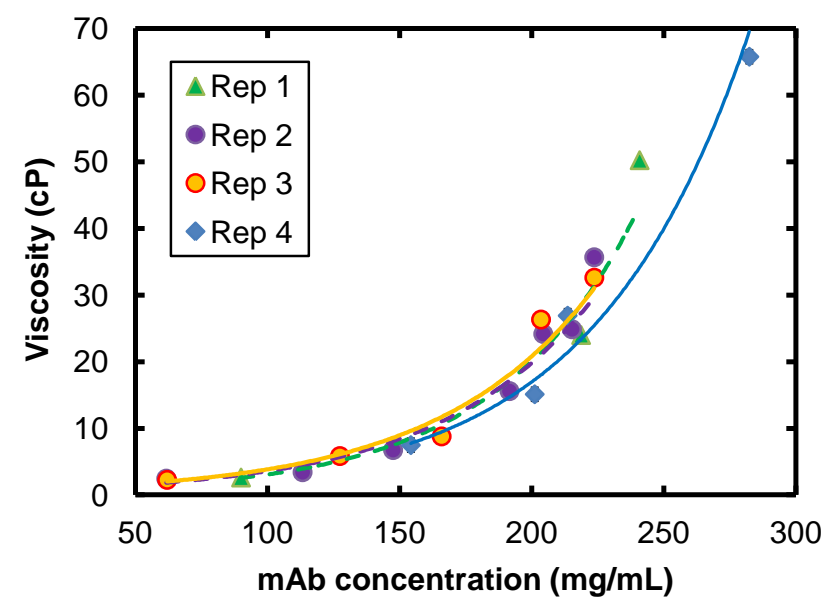

(a)

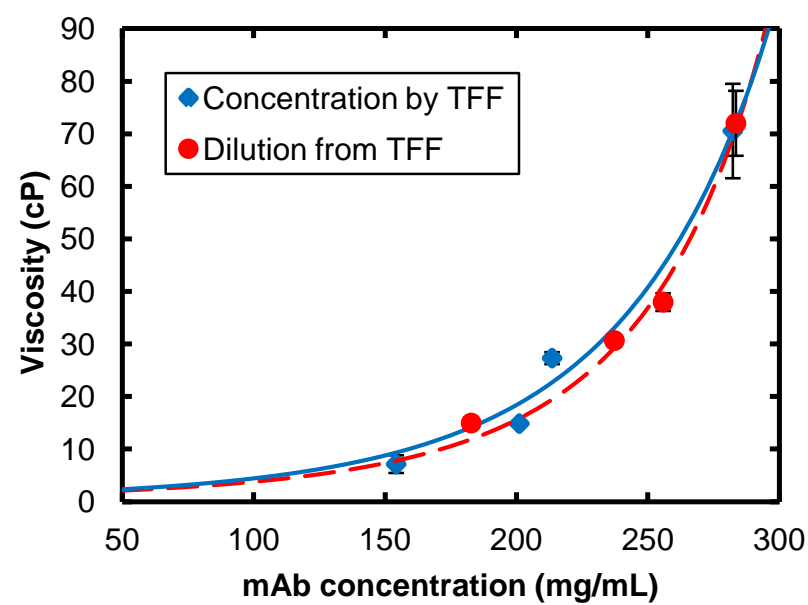

(b)

Figure 2. Relative reproducibility and reversibility of the 40:50:17 mg/mL Tre-His-CitrA mAb solution viscosity at pH 6. (a) Viscosity of the Tre-His-CitrA system as a function of four diafiltration conditions as described in Table 4. (b) Reversibility of Replicate 4 mAb solution viscosity between 150 and $280 \mathrm{mg} / \mathrm{mL}$ during concentration by TFF (-) and dilution in buffer (---). The colored lines are guides to the eye.

Low viscosities were obtained by ultrafiltration with four different TFF diafiltration conditions for the high co-solute Tre:His:CitrA formulation as shown in Table 4 and Fig. 2a. In 
replicates 2 and 3, buffer exchange was done at $65 \mathrm{mg} / \mathrm{mL} \mathrm{mAb}$ with a wall shear rate of 1405 or $8200 \mathrm{~s}^{-1}$, as indicated in Table 4. Replicate 3 was not relevant as it was highly turbid due to spallation from new tubing. Replicates 1 and 4 were buffer exchanged at the same shear rates as for 2 and 3, but with a lower concentration of $20 \mathrm{mg} / \mathrm{mL}$ and thus lower viscosity and shear stress. The concentration-normalized post-diafiltration turbidity of replicates 1, 2 and 4 increased linearly with the tubing wall shear stress*time, independent of the mAb concentration and applied wall shear stress (Fig. S4). The low turbidity of replicate 4 (due to the small tubing shear stress*time) indicates less irreversible aggregation during diafiltration; furthermore, it was the least viscous of the four replicates (Fig. 2a). There was also little hysteresis in the viscosity of replicate 4 upon dilution (Fig. 2b, Table S1), suggesting little gelation and irreversible aggregation during ultrafiltration, consistent with the lower turbidity [8]. Since soluble low-MW aggregates may not be fully removed by sterile filtration of the buffer-exchanged stock before ultrafiltration, these oligomers could lead to enhanced protein network formation during ultrafiltration. Thus, the reduction in irreversible aggregation during diafiltration, as indicated by the lower turbidity, may contribute to less pathway-dependent gelation during ultrafiltration.

\subsection{TFF membrane flux decay at high concentration}

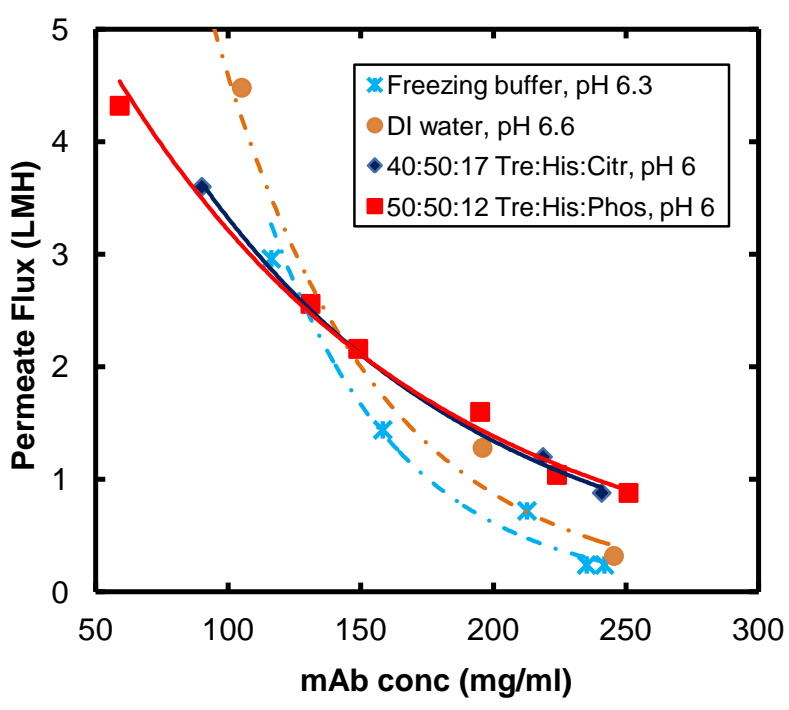

(a)

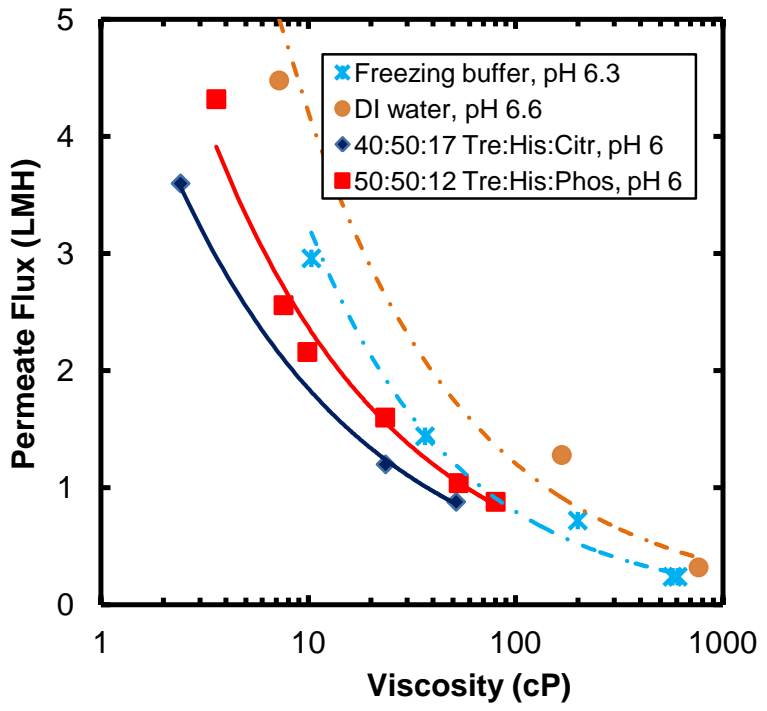

(b) 


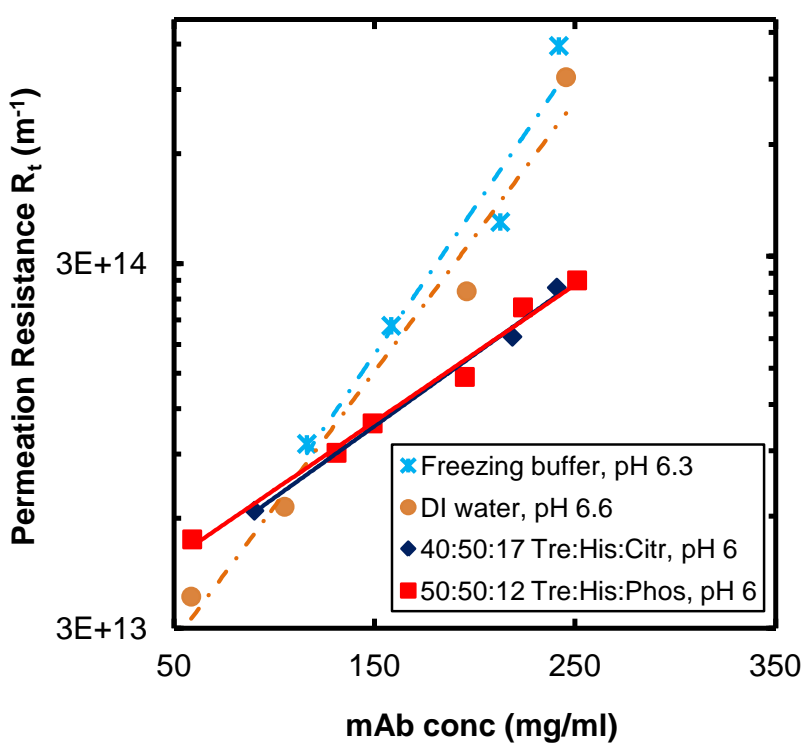

(c)

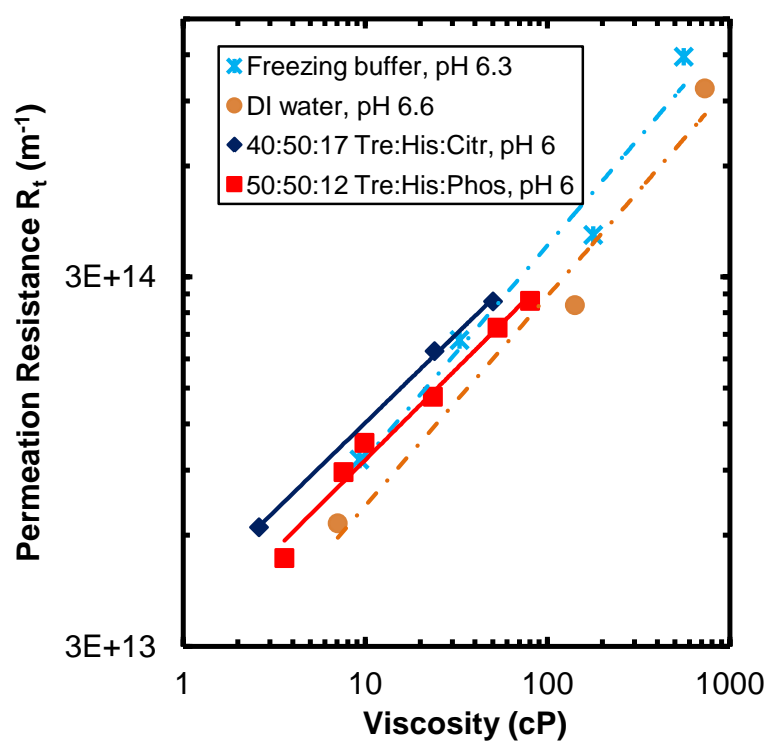

(d)

Figure 3. TFF membrane flux (in $\mathrm{L} / \mathrm{m}^{2} \mathrm{~h}$ ) as a function of (a) $\mathrm{mAb}$ concentration and (b) solution viscosity; and permeation flux resistance $R_{t}\left(\right.$ in $^{-1}$ ) as a function of (c) $\mathrm{mAb}$ concentration and (d) solution viscosity during ultrafiltration to $250 \mathrm{mg} / \mathrm{mL} \mathrm{mAb}$ for low co-solute (- - -) and high cosolute (-) solutions. The numbers in the formulation names represent concentration of each excipient in $\mathrm{mg} / \mathrm{mL}$. The flux and resistance curves for the 40:50:17 mg/mL Tre:His:Citr solution corresponds to Replicate 1 . The colored lines are a guide to the eye, and correspond to the data series of the same color.

The high co-solute solutions will now be shown to exhibit significantly slower decay in membrane flux with increasing mAb concentration than the low co-solute solutions. The instantaneous flux was measured at the operating TMP of 0.80 bar. The permeate flux $J$ of the low co-solute and His high co-solute solutions is plotted against the mAb concentration in Fig. 3a, and for the analogous Im high co-solute solutions in Fig. S5a. The low co-solute solutions started with a higher membrane flux than the high co-solute solutions, likely due to a lower $\eta_{0}$. However, a crossover in the flux between the low and high co-solute formulations was seen at $130 \mathrm{mg} / \mathrm{mL}$ due to the slower flux decay of the high co-solute systems. At the final $\mathrm{mAb}$ concentration of $250 \mathrm{mg} / \mathrm{mL}$, the membrane flux for the high co-solute solutions was three times higher than that of the low co-solute systems. The flux decay from 60 to $250 \mathrm{mg} / \mathrm{mL}$ mAb was only 5-fold for the high co-solute solutions compared to the much larger 32-fold reduction for the low co-solute case. The membrane flux, $J$, was also normalized for differences in $\eta_{0}$ and plotted as the overall permeation resistance $R_{t}$ according to Eq. 3 .

$$
R_{t}=\frac{T M P}{J * \eta_{0}}
$$


The resistance was found to increase exponentially with the mAb concentration, as seen in Fig. 3c and Fig. S5c. The smaller slopes of the resistance curves for the high co-solute formulations (plotted on a log scale in Fig. 3c; Fig. S5c) are consistent with the slower rate of flux decay. The crossover in $R_{t}$ occurred at a slightly earlier mAb concentration of $\sim 110 \mathrm{mg} / \mathrm{mL}$ than the flux crossover, and $R_{t}$ was found to increase at a significantly slower rate for the high co-solute solutions.

Surprisingly, the low and high co-solute solutions were found to give similar fluxes as a function of the solution viscosity, as shown in Fig. 3b (imidazole shown in Fig. S5b). The low co-solute solutions again start at a higher flux at low viscosity, but no flux crossover is observed. Instead, the low and high co-solute flux profiles approximately converge at high viscosities. When the flux was normalized for $\eta_{0}$ via the permeation resistance, the resistance curves nearly collapsed into a universal curve, as shown in Figure 3d and Fig. S5d. This result is interesting since a given viscosity corresponded to greatly different $\mathrm{mAb}$ concentrations for the low and high co-solute solutions. The apparent correlation between the solution viscosity and flux may also reflect the effect of viscosity on the axial TMP profile and resultant flux, as will be discussed later.

The difference in flux decay between the low and high co-solute solutions will now be examined in terms of the components of flux decay - membrane fouling (pore blocking and cake formation) and concentration polarization. To investigate membrane fouling, we compared the post-ultrafiltration reduction in the membrane normalized water permeability (NWP) caused by irreversibly-adsorbed mAb. The fouled membrane was first flushed with DI water for ten minutes to wash off reversibly adsorbed $\mathrm{mAb}$ and remove the concentration polarization gel layer before the NWP measurement. For the low and high co-solute solutions, the NWP reduction due to fouling by irreversibly adsorbed mAb was comparable at $\sim 60-70 \%$, as seen in Table 5, with the exception of the Tre:His:CitrA solutions. The Tre:His:CitrA formulation, which was the least viscous formulation, consistently exhibited a smaller NWP reduction of $30 \%$. No clear trend was found between the mass of mAb lost to irreversible adsorption on the membrane (which varied between 100 and $300 \mathrm{mg}$ mAb, based on the mass that was unaccounted for after recovery of the mAb in the solution and filter wash water) and the NWP reduction. The comparable NWP reductions suggest that the TFF filter membrane underwent 
similar degrees of fouling under both low and high co-solute conditions. Consequently, the large differences in the flux decline of the two types of solutions must be explained in part by concentration polarization.

The similar flux decay rates between the low and high co-solute solutions as a function of viscosity, $\eta$, (Fig. 3b) will now be explained in terms of concentration polarization. The expected transmembrane flux after accounting for concentration polarization is given by $[6,57]$

$$
J=\frac{D_{v}}{\delta} \ln \left(\frac{c_{w}}{c_{b}}\right)=k_{c} \ln \left(\frac{c_{w}}{c_{b}}\right)=k_{c} \ln \left(c_{g}\right)-k_{c} \ln \left(c_{b}\right)
$$

where $k_{c}$ is the mass transfer coefficient, $c_{b}$ is the bulk protein concentration and $c_{w}$ is the protein concentrations at the membrane wall, which at high protein concentrations is generally assumed to be equal to the gel limit $c_{g}$ [58]. As is apparent from Eq. 4, the constants $k_{c}$ and $c_{g}$ may be obtained from a linear fit of the flux as a function of $\ln \left(c_{b}\right)$, where the slope is equal to $-k_{c}$ and the $\mathrm{y}$-intercept is equal to $k_{c} \ln \left(c_{g}\right)$.

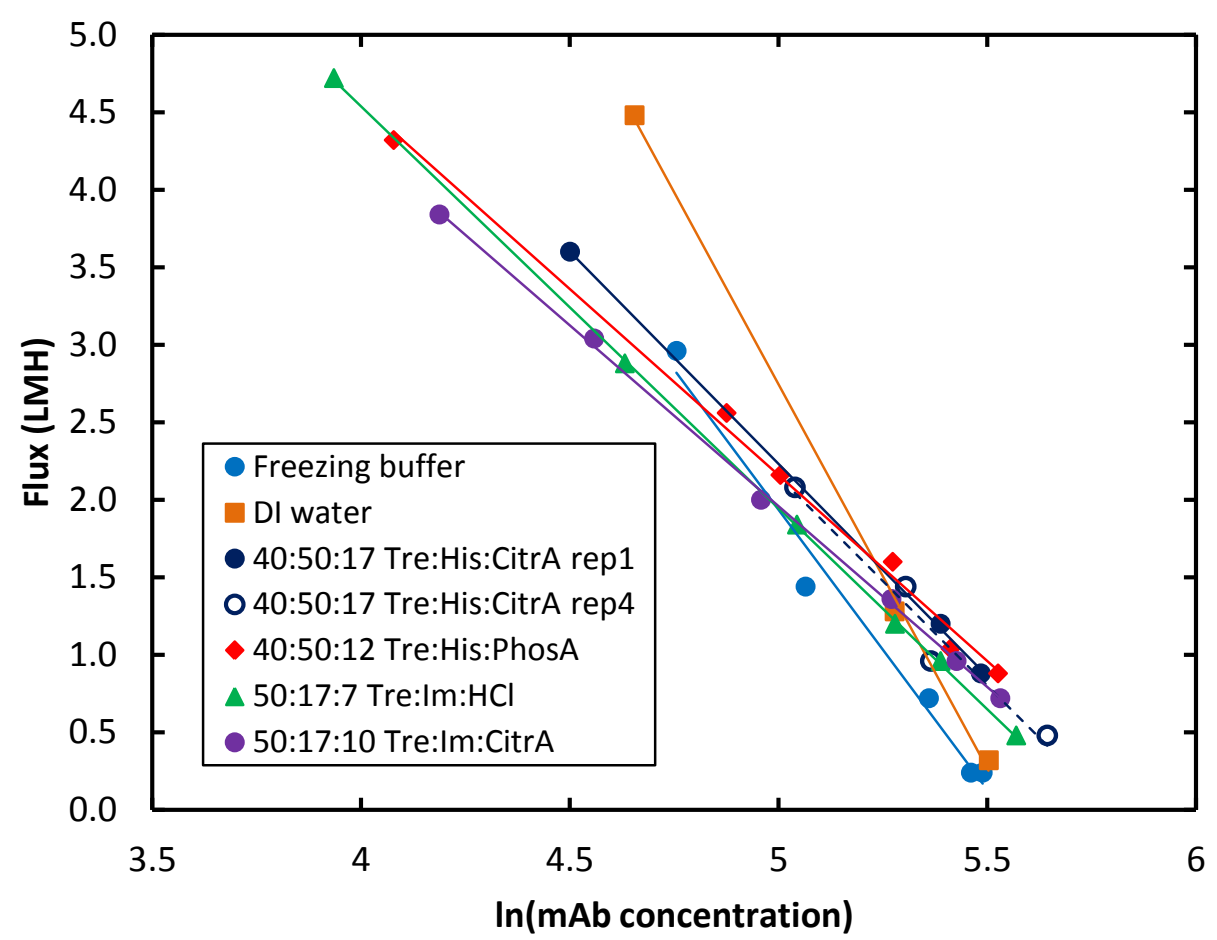

(a) 


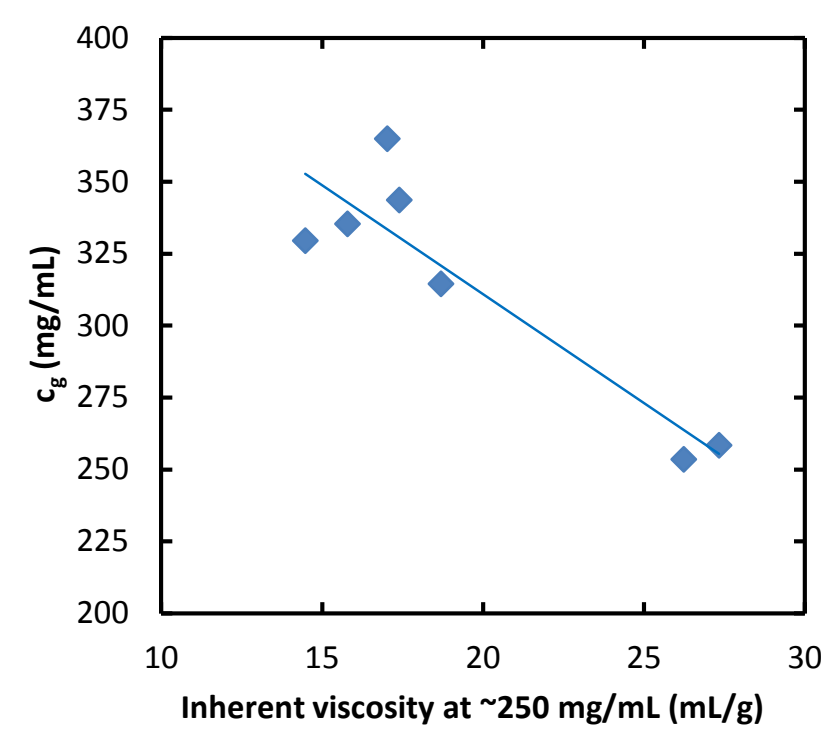

(b)

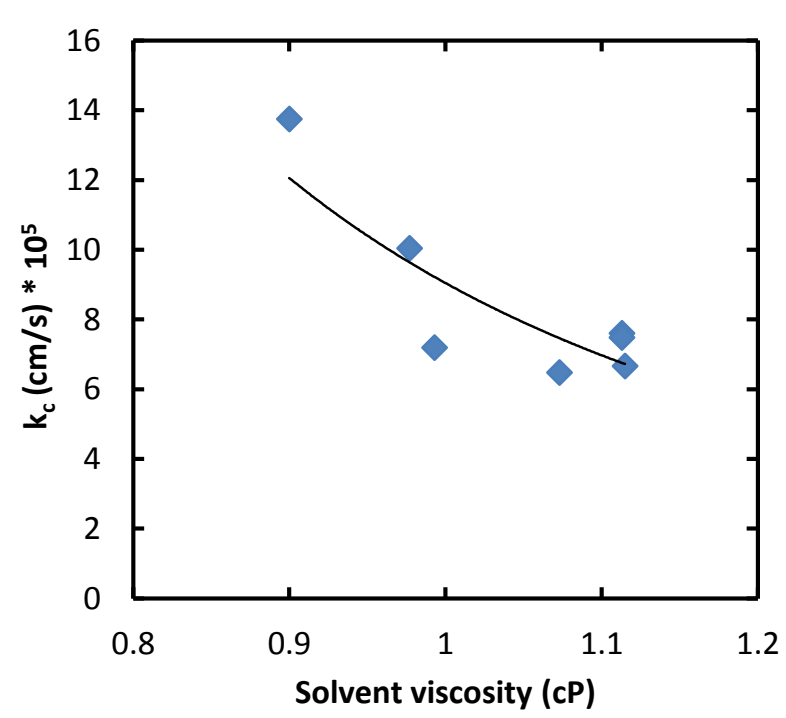

(c)

Figure 4. (a) TFF membrane flux (in $\mathrm{L}^{2} / \mathrm{m}^{2} \mathrm{~h}$ ) as a function of the natural logarithm of the mAb concentration. (b) Fitted gel point concentration $c_{g}$ and corresponding mAb inherent viscosity at $\sim 250$ $\mathrm{mg} / \mathrm{mL}$. (c) Fitted mass transfer coefficient $k_{c}$ and corresponding protein-free solvent viscosity. The lines are a guide to the eye.

From the linearized flux profiles (Fig. 4a), the $c_{g}$ 's were greater than $315 \mathrm{mg} / \mathrm{mL}$ (Table 6) for high co-solute concentrations compared to only $250 \mathrm{mg} / \mathrm{mL}$ at low concentrations. The $c_{g}$ increased with a decrease in the inherent viscosity (Fig. 4b), as co-solutes weakened attractive PPI, reducing network formation and $\mathrm{mAb}$ viscosity. Interestingly, the $k_{c}$ decreased slightly with increasing co-solute concentration as the solvent viscosity increased (Fig. 4c). As such, the larger flux of the high co-solute systems at high mAb concentration can be attributed in part to the enhanced rate of back-diffusion near the membrane wall, which is directly correlated with the filtrate flux at system equilibrium [59], as a result of the higher $c_{g}$ and therefore concentration polarization. 


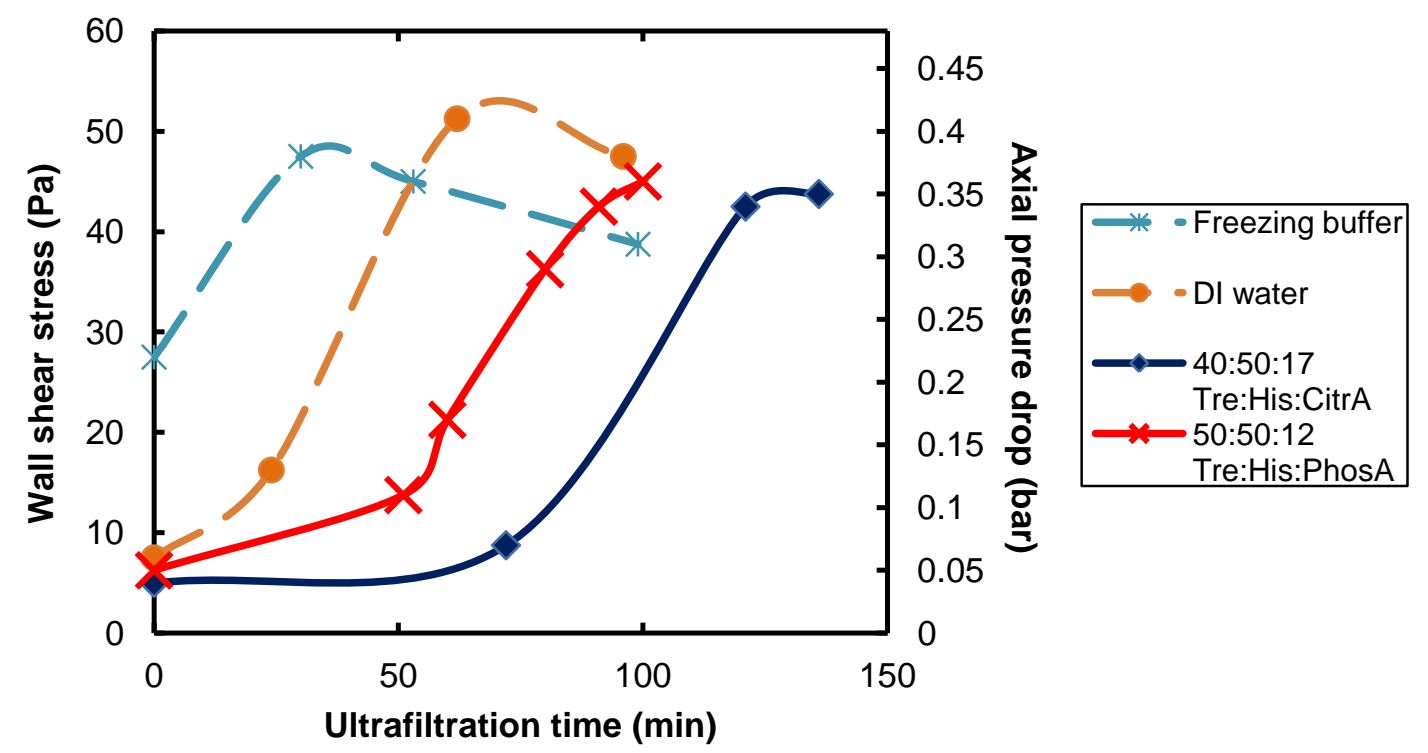

(a)

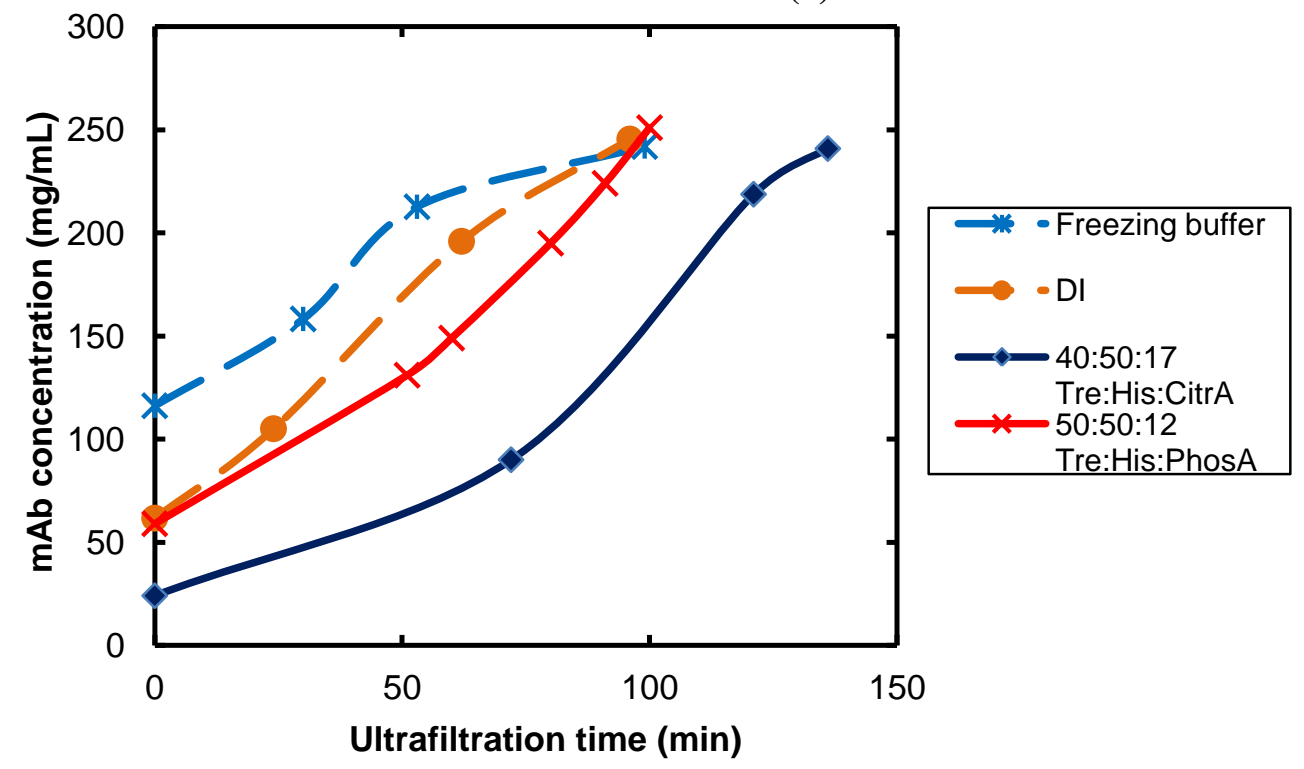

(b)

Figure 5. Time evolution of (a) pressure drop and wall shear stress and (b) mAb concentration during TFF ultrafiltration for low co-solute (---) and high co-solute solutions (-). The numbers in the formulation names represent concentration of each excipient in $\mathrm{mg} / \mathrm{mL}$. The concentration and pressure/shear stress curves for the 40:50:17 mg/mL Tre:His:Citr solution corresponds to Replicate 1.

We now demonstrate that the low viscosity, high co-solute solutions additionally resulted in improved control of the wall shear stress, $\tau_{w}$, during ultrafiltration. The $\tau_{w}$ was calculated from the measured $\triangle P($ Eq. 5)

$$
\tau_{w}=\frac{d_{H} \Delta P}{4 L}
$$


where $d_{H}$ is the hydrodynamic diameter of the flow channel and $L$ is the axial length of the filter module. As seen in Fig. 5a, $\triangle P$ slowly increased from 0.04 bar to $0.05-0.12$ bar during the first 60 minutes of ultrafiltration due to the increase in viscosity as the mAb was concentrated from 60 to $100 \mathrm{mg} / \mathrm{mL}$ (Fig. $5 \mathrm{~b}$ ), as follows from the Hagen-Poiseuille equation

$$
\frac{\Delta P}{L}=\frac{8 \eta Q}{\pi R^{4}}
$$

where $Q$ is the volumetric cross-flow rate and $R$ is the diameter of the individual hollow fiber. The $\Delta P$ then increased rapidly to 0.35 bar due to the exponential viscosity increase between 100 and $200 \mathrm{mg} / \mathrm{mL} \mathrm{mAb}$. Once $\Delta P$ reached $0.35 \mathrm{bar}$, the cross-flow rate was gradually reduced to maintain a constant $\Delta P$ to prevent the pressure at the filter inlet from exceeding the module pressure rating. The corresponding $\tau_{w}$ increased slowly from 5 to $15 \mathrm{~Pa}$, as seen in Fig. $5 \mathrm{a}$, and then rapidly rose to a maximum value of $40 \mathrm{~Pa}$ before leveling off. In contrast, the $\tau_{w}$ for the low co-solute solution (freezing buffer) and DI water quickly increased to a maximum of $50 \mathrm{~Pa}$ at $150-160 \mathrm{mg} / \mathrm{mL}$ before decreasing with further increases in the mAb concentration, as discussed in the Supporting Information (Section 6.6). The shear and concentration profiles of the Im systems are similar to those of the His systems, as seen in Fig. S6a and S6b. With the low viscosity of the high co-solute systems, $\tau_{w}$ stayed below $40 \mathrm{~Pa}$ up to $200 \mathrm{mg} / \mathrm{mL}$, whereas this threshold was exceeded at only $150-160 \mathrm{mg} / \mathrm{mL}$ for the viscous, low co-solute systems.

The hollow fiber filter geometry will now be shown to enable a more uniform TMP and low wall shear stress $\tau_{w}$ for maintaining a high transmembrane flux. A low $\tau_{w}$ of $5-50 \mathrm{~Pa}$ was maintained throughout ultrafiltration to $250 \mathrm{mg} / \mathrm{mL}$ with the hollow fiber module (Fig. 5a), and was sufficient to prevent rapid flux decline. In contrast, in TFF studies utilizing flat sheet cassettes, a higher $\tau_{w}$ of $200-400 \mathrm{~Pa}$ was applied to maximize membrane flux at mAb concentration greater than $50 \mathrm{mg} / \mathrm{mL}[6,8]$ and maintain a high initial TMP. As described in the Supporting Information (Section 6.8), the lower $\tau_{w}$ in this study may be attributed to the use of hollow fibers with a large inner diameter of $1.0 \mathrm{~mm}$. In general, for the same bulk velocity and flow channel cross-sectional area in open flow channels, the hollow fiber may be expected to have higher pressure drops and wall shear stresses than cassettes by factors of 4.19 and 1.67 respectively (Section 6.8). However, in screened cassettes, such as the commonly used Pellicon (Millipore) modules, additional parasitic pressure losses due to the screens as well as sharp turns 
where $P_{i}$ and $P_{o}$ are the filter inlet and outlet pressures, respectively, and $P_{p}$ is the permeate pressure. In our case, the low viscosities of our concentrated solutions as well the hollow fiber geometry resulted in a small $\Delta P$ (Fig. 5a). Since $\Delta P$ was the controlling parameter for tuning the TMP and $\tau_{w}$ (Eq. 5; Eq. 7), the low $\Delta P$ led to a small $\tau_{w}$, and more uniform axial TMP profile (Fig. S7). Consequently, we were able to maintain the TMP at a low level without the need to adjust the cross-flow rate throughout ultrafiltration.

The more uniform axial TMP profiles may also contribute to the higher fluxes for the high co-solute systems. As described by Binabaji et al. [12], a significant portion of the reversible flux decline at high concentration can be attributed to a steep decline in the local TMP near the back end of the filter device, resulting in reduced local fluxes. When the local TMP falls below the osmotic back-pressure, back-filtration significantly reduces the overall flux. In this study, the local TMP remained above the osmotic pressure at all mAb concentrations (Fig. S7), but a noticeable difference in the normalized TMP ( $\left.\mathrm{TMP}_{\text {local }} / \mathrm{TMP}_{\text {average }}\right)$ profile can be seen between the high and low co-solute systems between 100 and $200 \mathrm{mg} / \mathrm{mL} \mathrm{mAb}$ (Fig. S7a, S7b). 

1.0 (local TMP = average TMP when the normalized TMP =1.0). The average TMP was set at the knee-point value of 0.8 bar, as described in Section 6.7 in the Supporting Information. Consequently, the local TMP for the low co-solute systems fell below the pressure-independent region (corresponding to normalized TMP < 1.0) more steeply in the rear section of the hollow fiber, which may explain the lower flux above $100 \mathrm{mg} / \mathrm{mL} \mathrm{mAb}$. However, while hollow fibers offer the advantage of more uniform flow paths and TMP profiles, they still have lower fluxes than flat sheet devices. The longer filtration times may be detrimental for maintaining protein quality.

\subsection{Turbidity of high concentration $m A b$ solution}

The solution turbidity of the 40:50:17 mg/mL Tre:His:CitrA solution (replicate 4) was measured after 3 months of storage at $4^{\circ} \mathrm{C}$, during which mild evaporative losses caused an increase in the $\mathrm{mAb}$ concentration to $300 \mathrm{mg} / \mathrm{mL}$. For a path length of $0.2 \mathrm{~cm}$, the absorbance at $300 \mathrm{mg} / \mathrm{mL}$ at $350 \mathrm{~nm}$ was 0.165 , corresponding to a turbidity of $0.826 \mathrm{AU}^{*} \mathrm{~cm}^{-1}$ and a concentration-normalized turbidity of $0.0027 \mathrm{AU}^{*} \mathrm{~mL}^{*} \mathrm{mg}^{-1} \mathrm{~cm}^{-1}$, as reported in Table 7. The relatively low turbidity at $300 \mathrm{mg} / \mathrm{mL}$ in the current study likely resulted from the low solution $\eta$, axial $\Delta P$ and $\tau_{w}$, which minimized the tendency for protein aggregation. The low levels of irreversible aggregation may also be favorable for reducing pore blocking and cake formation [61].

Sterile filtration of the $300 \mathrm{mg} / \mathrm{mL}$ mAb solution resulted in a decrease in concentration to $223 \mathrm{mg} / \mathrm{mL}$, due to the presence of entrained water in the washed syringe filter membrane. The resulting absorbance at $350 \mathrm{~nm}$ was $0.0743 \mathrm{AU}$, corresponding to a turbidity of 0.372 $\mathrm{AU}^{*} \mathrm{~cm}^{-1}$ and a concentration-normalized turbidity of $0.0017 \mathrm{AU}^{*} \mathrm{~mL}^{*} \mathrm{mg}^{-1} \mathrm{~cm}^{-1}$ (Table 7). The two-fold reduction in turbidity corresponded with a decrease in $\eta_{i n h}$ from 15.7 to $13.4 \mathrm{~mL} / \mathrm{g}$, which may be explained in part by the dilution of the mAb. The normalized effective $D_{v}$ from DLS increased from 0.26 to 0.31 after sterile filtration as indicated in Table S2, which may be due in part to the lower mAb concentration [62], but which may also suggest removal of larger aggregates, consistent with the smaller contribution to the DLS autocorrelation function at long times (Fig. S11). Although the removal of large aggregates by sterile filtration has been seen in literature to reduce the low-shear $\left(<\sim 300 \mathrm{~s}^{-1}\right)$ viscosity and eliminate the shear-thinning behavior 
of a concentrated IgG1 mAb [63] this does not appear to be the case for the Tre:His:CitrA solution. Both large irreversible [63] and small reversible aggregates [4, 11, 29, 30, 32, 64-66] are thought to promote protein network formation which leads to high viscosities. It is likely that in this case, network formation was sufficiently suppressed by the high His/Im levels (as will be described in the Discussion section), given the relatively low mAb viscosity.

\section{$3.4 \mathrm{pH}$ shift during ultrafiltration}

The high co-solute solutions underwent a negligible $\mathrm{pH}$ shift during ultrafiltration compared to the low co-solute solutions, remaining essentially constant during ultrafiltration from 60 to $250 \mathrm{mg} / \mathrm{mL}$ as shown in Fig. S8. Additionally, intermediate $\mathrm{pH}$ measurements during ultrafiltration of a representative high co-solute solution (50:17:10 mg/mL Tre:Im:CitrA) revealed a negligible difference in the $\mathrm{pH}$ of the retentate and permeate streams (shift of $\sim 0.02$ units), both of which remained constant at 7.0 as seen in Table S3. The matching, unchanging pH in the permeate and retentate streams over the entire $\mathrm{mAb}$ concentration range suggests that the charged buffer species (His, Im, counteracids) did not partition significantly across the membrane during filtration [9]. The solution $\mathrm{pH}$ was in good agreement with the initial $\mathrm{pH}$ of the protein-free buffer, although a small shift of $<0.1$ units was observed for the buffers prepared at pH 6.5 and 7 as seen in Table S4 due to the self-buffering capacity of the mAb [67]. In contrast, a more noticeable $\mathrm{pH}$ shift of 0.2 units from 60 to $240 \mathrm{mg} / \mathrm{mL}$ was observed during filtration of the low co-solute solutions, suggesting partioning of the buffer species across the membrane due to the Donnan effect [9] or electrical double-layer volume exclusion $[10,68]$.

\section{5 mAb stability in the ultraconcentrated solutions}

The high co-solute solutions will now be shown to be stable against irreversible aggregation during manufacture and storage at $4^{\circ} \mathrm{C}$, as assessed by size exclusion chromatography (SEC). The monomer content was assessed as both (i) the ratio of monomer to monomer + soluble aggregates (“\% monomer") and (ii) the mass ratio of recovered monomer for the post-TFF/storage to the pre-TFF/storage samples ("monomer recovery"). SEC measurements of the $250 \mathrm{mg} / \mathrm{mL}$ solutions after $2-4$ weeks of storage at $4^{\circ} \mathrm{C}$ show similarly low levels of soluble irreversible aggregates for both the low and high co-solute solutions, with less than $1 \%$ soluble aggregates upon dilution to $2 \mathrm{mg} / \mathrm{mL}$, as seen in Table 8 . The only exception was the 
Tre:Im:CitrA solution, which showed $2.6 \%$ soluble aggregates when measured after 7 months of storage at $4{ }^{\circ} \mathrm{C}$. However, a significant difference in the insoluble aggregate content was seen between the low and high co-solute solutions, with monomer recoveries of $\sim 90 \%$ with high cosolute and $60-80 \%$ with low co-solute formulations. Visible gel-like aggregates were observed during dilution of the concentrated low co-solute solutions. These large irreversible aggregates were filtered out during SEC sample preparation, but account for the significantly lower recoveries. The ultrahigh viscosity of the low co-solute solutions may explain the low monomer recoveries, as the viscous solutions may undergo greater pathway-dependent gelation and irreversible aggregation during ultrafiltration.

To more extensively test storage stability, Replicate 4 of the Tre:His:CitrA solution was stored over 8 weeks at $-40^{\circ} \mathrm{C}, 4^{\circ} \mathrm{C}$ and $37^{\circ} \mathrm{C}$. Due to evaporative losses during storage, especially at $37^{\circ} \mathrm{C}$, the concentrations increased in some cases. Despite the high mAb concentrations, $\eta$ remained below $100 \mathrm{cP}$ for a majority of the stored samples and changes in $D_{\sqrt{ }} / D v_{, o}$ were negligible as indicated in Table S5. The $\eta_{\text {inh }}$ of the samples stored at $-40^{\circ} \mathrm{C}$ and $4^{\circ} \mathrm{C}$ was relatively constant as seen in Fig. S9a, whereas $\eta_{i n h}$ at $37^{\circ} \mathrm{C}$ decreased from $16.9 \mathrm{~mL} / \mathrm{g}$ at 4 days to $14.5 \mathrm{~mL} / \mathrm{g}$ at 28 days (Table 9). At each temperature, the soluble aggregate content was $\leq 0.8 \%$ even after up to 4 weeks at $37^{\circ} \mathrm{C}$ and 8 weeks at $-40^{\circ} \mathrm{C}$ and $4^{\circ} \mathrm{C}$ (Table 9; Fig. S9b). The monomer recovery after storage was also assessed relative to the original concentrated dispersion before accelerated storage tests. As seen in Table 9, the monomer recovery remained high at $\sim 90 \%$ throughout the entire storage period of up to 8 weeks, even at the highest storage temperature of $37^{\circ} \mathrm{C}$.

The concentrated high co-solute solutions also remained clear at low temperature, even after up to four months of storage at $4^{\circ} \mathrm{C}$ as shown in Fig. S9c. In contrast, the low co-solute solutions became cloudy and formed a rigid, opaque gel within minutes of exposure to the $4^{\circ} \mathrm{C}$ environment, as shown in Fig. S9d. Although the gelled solution returns to a liquid state upon being warmed to room temperature, irreversible phase separation was evident. It is likely that the concentrated co-solute shielded various charged patches and hydrophobic sites on the protein to inhibit gelation and the formation of aggregates during storage.

\subsection{Mechanism of Viscosity Reduction}


At concentrations of $250 \mathrm{mg} / \mathrm{mL}$ ( $20 \%$ volume fraction) when the spacing between proteins is on the order of the molecular diameter [69], the relationship between viscosity and protein interactions is highly complex and not very well understood. Even with a range of techniques including SANS [32, 65, 70-73], SAXS [32], SLS [2], DLS [74-76], simulation [7780], rheological studies [4, 11, 27-29, 63, 73, 81-84] and combinations thereof, relatively little is known about the interactions and structure of protein solutions at high concentrations. From a rheological point of view, the significant reduction in $[\eta]$ and $\eta_{i n h}$ of the concentrated $\mathrm{mAb}$ the high co-solute systems (Tables 1 - 3) may offer insight into the weakening of attractive protein interactions that contribute to high solution viscosities.

The significant reduction in viscosity for the $\mathrm{mAb}$ in this study resulting from the addition of histidine and imidazole (Figure 1, Table $2-3$ ) will now be examined in terms of modifications in the protein-protein interactions modified by these two co-solutes. The viscosity of antibody solutions has been shown to increase with the formation of small reversible lowdensity clusters or networks of interacting [28, 32, 64, 65] or physically entangled [85] mAb molecules. Network formation and aggregation may be mediated by local anisotropic attractive electrostatic and hydrophobic interactions. The addition of co-solutes may generate significant viscosity reductions by disruption of these interactions through shielding of charged [32, 65] and hydrophobic sites [36] on the protein surface. Inorganic salts such as $\mathrm{NaCl}$ have been shown in some cases to reduce $\mathrm{mAb}$ viscosity by weakening local attractive electrostatic interactions [4, $11,32]$, but have also been found to increase the viscosity [41], likely by amplifying the strength of hydrophobic interactions [86]. The charged amino acid arginine (Arg) is also known to both stabilize [87] and greatly reduce the viscosity for some proteins [28, 37, 41-43, 88] by shielding both electrostatic and hydrophobic residues on the protein surface $[46,87,89,90]$. The significant viscosity reduction from the addition of $300 \mathrm{mM}$ His in this study (Fig. 1, Tables 2 3) may be caused by a similar mechanism as Arg, given their similar charge and molecular structure. In contrast, the addition of $150 \mathrm{mM} \mathrm{NaCl}$ caused a much smaller reduction in viscosity (Table 1), despite comparable solution ionic strengths. Recent membrane osmometry [43] and light scattering studies [45] suggest that co-solute effects on the viscosity of highly concentrated $\mathrm{mAb}$ occurs through modification of local rather than global interactions, and in some cases via co-solute binding to the mAb surface [45]. The preferential interaction of some co-solutes with 
the mAb may therefore explain the differences in co-solute effects on viscosity for co-solutes with similar charge and solution ionic strength.

The potent ability of histidine and imidazole to mitigate attractive protein-protein interactions and reduce the concentrated mAb viscosity by up to ten-fold (Fig. 1) will be explained in terms of their unique specific interactions with charged and hydrophobic residues on the protein surface. Histidine is positively charged below $\mathrm{pH} 6$ and slightly hydrophobic with a Hopp-Woods hydrophobicity index of -0.5 , where a negative index indicates an apolar residue in a protein sequence [91]. Below pH 6, the cationic imidazole group is capable of shielding negatively-charged sites on the mAb surface via ion-pairing. Both His and Im also exhibit strong, selective binding affinities for the Arg and His residues on the protein surface [46]. Molecular dynamics (MD) simulations have shown that positively-charged His is capable of pairing with both neutral and positively-charged His and Arg residues on the protein surface despite the Coulombic repulsion between like-charged pairs [46]. The ability of His to form like-charged pairs with itself and Arg is thought to be due to stacking of the conjugated imidazole and guanidyl side chains respectively [46]. As a result, His is capable of neutralizing negativelycharged residues through Coulombic attraction while blocking neutral and positively-charged His and Arg residues through stacking of the conjugated side chains, leading to its efficacy in screening anisotropic attractive electrostatic interactions. Beyond charge-shielding effects, His has also been shown via simulations to interact with hydrophobic aromatic residues via ion- $\pi$ interactions through the imidazole group [92, 93]. Due to the zwitterionic functional groups on His, the imidazole-aromatic interaction is effectively able to convert a hydrophobic surface patch to a hydrophilic one [94], weakening the hydrophobic interactions. In contrast, the inorganic salt $\mathrm{NaCl}$ does do not undergo specific binding with the protein and cannot mitigate local anisotropic interactions. The significantly greater viscosity reduction by His and Im (Fig. 1, Table $2-$ 3), versus $\mathrm{NaCl}$ at comparable ionic strength (Table 1), therefore likely arose from more efficient modulation of the local anisotropic attractive electrostatic and hydrophobic interactions. The very high concentrations of His and Im along with Tre also further perturb the electrostatic and hydrophobic interactions by the high degree of depletion attraction. In addition, the preferential exclusion of Tre from the surface favors folding for enhanced protein stability $[95,96]$.

\section{CONCLUSIONS}


For concentrated 250 to $280 \mathrm{mg} / \mathrm{mL}$ mAb solutions formed by TFF, the solution viscosity was reduced from $300 \mathrm{cP}$ to $40-80 \mathrm{cP}$ in systems containing high concentrations of the cosolutes histidine or imidazole. At the highest protein concentrations, the transmembrane fluxes were two to threefold higher with the high co-solute concentrations. This gain in transmembrane flux was due in part to a significant increase in the protein $c_{g}$ (gel point concentration) and the consequent enhancement of concentration polarization-driven back-diffusion near the membrane wall. The difference in the flux at high protein concentrations was not attributable to membrane fouling, as the normalized water permeability reductions were similar for high and low co-solute systems. For all co-solute concentrations, similar slopes were obtained for a wide range of systems on a log-log plot of permeation resistance (flux normalized by $\eta_{0}$ at constant TMP) versus viscosity over three orders of magnitude in viscosity, indicating the important role of viscosity in regards to flux decay.

With the low viscosities for high co-solute concentrations, the smaller axial $\Delta P$ resulted in a smaller and more uniform $\tau_{w}$, as well as a more uniform TMP. An advantage of the hollow fiber geometry is the uniform flow path, unlike the serpentine channels with $90^{\circ}$ bends found in flat sheet cassettes that can generate high local $\Delta P$ and shear stresses. The more uniform $\tau_{w}$ and TMP are expected to be beneficial for minimizing the rate of reversible flux decline.

Furthermore, the concentrated protein solutions with either concentrated histidine or imidazole as co-solutes had less than $1 \%$ soluble aggregates by SEC and a high monomer recovery of $~ 90 \%$, in contrast with the low recoveries of $60-80 \%$ for the low co-solute solutions. The high monomer recovery corresponded with slower reversible flux decline. Under extended storage at $40^{\circ} \mathrm{C}, 4^{\circ} \mathrm{C}$ and $37^{\circ} \mathrm{C}$, the soluble aggregate content remained below $1 \%$ after 4 weeks at all three storage temperatures for the trehalose-histidine-citric acid system. The high histidine concentration also solubilized the $\mathrm{mAb}$ and prevented precipitation of the $250 \mathrm{mg} / \mathrm{mL}$ solution at $4^{\circ} \mathrm{C}$, whereas the onset of gelation and precipitation was almost immediate for the concentrated low co-solute solutions.

\section{ACKNOWLEDGEMENTS}

The authors would like to acknowledge Muhammad W. Lubis and Anuj K. Kudva for their assistance with some of the mAb concentration measurements. The mAb used in this study was provided by AbbVie Inc. The University of Texas at Austin received research funds from 


\begin{abstract}
AbbVie Inc. to conduct the study. AbbVie provided financial support and the antibody used in this study. Additional support was provided by the Welch Foundation F-1319 and F-1696 and NSF (CBET-1247945).
\end{abstract}


Table 1. Viscosity $(\eta)$ and filtration times for low co-solute control solutions made by centrifugation filtration (CF). The diafiltration (DF) time corresponds to buffer exchange into 6 diavolumes and subsequent concentration to $\sim 80 \mathrm{mg} / \mathrm{mL} \mathrm{mAb}$. The ultrafiltration (UF) time corresponds to concentration from $\sim 80 \mathrm{mg} / \mathrm{mL}$ to $250 \mathrm{mg} / \mathrm{mL}$. No diafiltration step was required for the controls in the freezing buffer. The inherent viscosity $\eta_{i n h}$ was calculated from $\eta$ and the measured solvent viscosity $\eta_{0}$.

\begin{tabular}{|c|c|c|c|c|c|c|c|c|c|c|c|c|c|}
\hline $\begin{array}{c}\mathrm{mAb} \\
\text { conc } \\
(\mathrm{mg} / \mathrm{mL})\end{array}$ & Exc 1 & $\begin{array}{c}\text { Exc } 1 \\
\text { conc } \\
(\mathrm{mM}) \\
\end{array}$ & Exc 2 & $\begin{array}{c}\text { Exc } 2 \\
\text { conc } \\
(\mathrm{mM}) \\
\end{array}$ & $\operatorname{Exc} 3$ & $\begin{array}{c}\text { Exc 3 } \\
\text { conc } \\
(\mathbf{m M}) \\
\end{array}$ & $\mathbf{p H}$ & $\begin{array}{c}\eta \\
(\mathbf{c P})\end{array}$ & $\begin{array}{c}\boldsymbol{\eta}_{0} \\
(\mathbf{c P})\end{array}$ & $\begin{array}{c}\eta_{\text {inh }} \\
(\mathbf{m L} / \mathbf{g})\end{array}$ & $\begin{array}{l}\text { Turbidity } \\
\left(\mathrm{AU}^{*} \mathbf{c m}^{-1}\right)\end{array}$ & $\begin{array}{c}\text { DF time } \\
(\text { min })\end{array}$ & $\begin{array}{c}\text { UF time } \\
(\text { min })\end{array}$ \\
\hline $281 \pm 8.7$ & \multicolumn{6}{|c|}{ Freezing buffer (replicate 1) } & 6.1 & 424 & 0.98 & 21.6 & 0.376 & 0 & 75 \\
\hline $271 \pm 0.5$ & \multicolumn{6}{|c|}{ Freezing buffer (replicate 2) } & 6.1 & 460 & 0.98 & 22.7 & 0.388 & 0 & 75 \\
\hline $238 \pm 3.3$ & His & 30 & $\mathrm{HCl}$ & 19 & --- & --- & 6.2 & 188 & 0.98 & 22.1 & 0.388 & 70 & 54 \\
\hline $230 \pm 2.8$ & His & 30 & $\mathrm{HCl}$ & 19 & $\mathrm{NaCl}$ & 150 & 6.0 & 61 & 0.98 & 18.0 & 0.581 & 85 & 69 \\
\hline
\end{tabular}


Table 2. Viscosity $(\eta)$ and filtration times of low and high co-solute solutions made by tangential flow filtration (TFF). The inherent viscosities $\left(\boldsymbol{\eta}_{\text {inh }}\right)$ were evaluated at the final $\mathrm{mAb}$ concentration $(\sim 250 \mathrm{mg} / \mathrm{mL})$, while the intrinsic viscosity $[\eta]$ and combined crowding-Simha shape factor $k / v$ were fit from the viscosity profile. Alternating shaded rows indicate different formulations. The $280 \mathrm{mg} / \mathrm{mL} \mathrm{replicate} \mathrm{of} \mathrm{the}$ 40:50:17 mg/mL Tre:His:CitrA solution corresponds to Replicate 4 and the $241 \mathrm{mg} / \mathrm{mL}$ replicate corresponds to Replicate 1 (Figure 2).

\begin{tabular}{|c|c|c|c|c|c|c|c|c|c|c|c|c|c|c|c|c|}
\hline \multirow{2}{*}{$\begin{array}{c}\text { mAb } \\
\text { conc } \pm \\
\text { stdev } \\
(\mathbf{m g} / \mathbf{m L})\end{array}$} & \multicolumn{2}{|c|}{ Tre conc } & \multirow{2}{*}{ Base } & \multicolumn{2}{|c|}{ Base conc } & \multirow{2}{*}{ Acid } & \multicolumn{2}{|c|}{ Acid conc } & \multirow{2}{*}{ pH } & \multirow{2}{*}{$\begin{array}{c}\eta \\
(\mathbf{c P})\end{array}$} & \multirow{2}{*}{$\begin{array}{c}\eta_{0} \\
(\mathbf{c P})\end{array}$} & \multirow{2}{*}{$\begin{array}{c}\eta_{\text {inh }} \\
(\mathrm{mL} / \mathrm{g})\end{array}$} & \multirow{2}{*}{$\underset{(\mathrm{mL} / \mathrm{g})}{[\eta]}$} & \multirow{2}{*}{$k / v$} & \multirow{2}{*}{$\begin{array}{c}\text { DF time } \\
\text { (min) }\end{array}$} & \multirow{2}{*}{$\begin{array}{c}\text { UF } \\
\text { time } \\
\text { (min) }\end{array}$} \\
\hline & $\begin{array}{l}\text { mg/ } \\
\text { mL }\end{array}$ & $\mathbf{m M}$ & & $\begin{array}{c}\mathrm{mg} / \\
\mathrm{mL}\end{array}$ & $\mathbf{m M}$ & & $\begin{array}{l}\mathrm{mg} / \\
\mathrm{mL}\end{array}$ & $\mathbf{m M}$ & & & & & & & & \\
\hline $242 \pm 2.5$ & \multicolumn{8}{|c|}{ Freezing buffer } & 6.4 & 559 & 0.98 & 26,2 & 16.3 & 0.0948 & $0^{\mathrm{a}}$ & 99 \\
\hline $245 \pm 3.6$ & \multicolumn{8}{|c|}{ DI water } & 6.7 & 729 & 0.93 & 27.2 & 20.6 & 0.0468 & 150 & 96 \\
\hline $282 \pm 3.7^{b, c}$ & 40 & 105 & His & 50 & 320 & CitrA & 17 & 80 & 6 & 66 & 1.11 & 14.5 & 12.1 & 0.0406 & $68^{d}$ & $373^{\mathrm{e}}$ \\
\hline $241 \pm 0.3^{b}$ & 40 & 105 & His & 50 & 320 & CitrA & 17 & 80 & 6 & 50 & 1.11 & 15.8 & 6.2 & 0.4030 & 253 & 136 \\
\hline $251 \pm 18.5$ & 50 & 130 & His & 50 & 320 & PhosA & 12 & 120 & 6 & 80 & 1.12 & 17.0 & 13.5 & 0.0556 & 270 & 100 \\
\hline $252 \pm 0.5$ & 50 & 130 & $\mathrm{Im}$ & 17 & 250 & CitrA & 10 & 50 & 7 & 86 & 1.07 & 17.4 & 11.1 & 0.1318 & 284 & 145 \\
\hline $262 \pm 4.5$ & 50 & 130 & $\mathrm{Im}$ & 17 & 250 & $\mathrm{HCl}$ & 7 & 190 & 6.4 & 133 & 0.99 & 18.7 & 11.9 & 0.112 & 243 & 147 \\
\hline
\end{tabular}

a. No diafiltration step was needed for the freezing buffer solution

b. The mAb solution was buffer exchanged at $20 \mathrm{mg} / \mathrm{mL}$ instead of $60 \mathrm{mg} / \mathrm{mL}$

c. The mAb solution was additionally degassed before diafiltration and ultrafiltration (optimized TFF procedure)

d. Buffer exchanged using a $115 \mathrm{~cm}^{2}$ area membrane (all other rows buffer exchanged with $75 \mathrm{~cm}^{2}$ membrane), leading to faster permeation rate

e. Larger sample volume ( $250 \mathrm{~mL}$ at start of ultrafiltration) compared to other rows $(50 \mathrm{~mL}$ at start of ultrafiltration) 
Table 3. Viscosity $(\eta)$ and filtration times for high co-solute solutions made by centrifugation filtration (CF). The diafiltration (DF) time corresponds to buffer exchange into 6 diavolumes and subsequent concentration to $\sim 80 \mathrm{mg} / \mathrm{mL} \mathrm{mAb}$. The ultrafiltration (UF) time corresponds to concentration from $\sim 80 \mathrm{mg} / \mathrm{mL}$ to $250 \mathrm{mg} / \mathrm{mL}$. The inherent viscosity $\eta_{i n h}$ was calculated from $\eta$ and the measured solvent viscosity $\eta_{0}$.

\begin{tabular}{|c|c|c|c|c|c|c|c|c|c|c|c|c|c|}
\hline $\begin{array}{c}\text { mAb conc } \pm \\
\text { stdev } \\
(\mathrm{mg} / \mathbf{m L})\end{array}$ & Exc 1 & $\begin{array}{l}\text { Exc 1 } \\
\text { conc } \\
(\mathbf{m M})\end{array}$ & Exc 2 & $\begin{array}{c}\operatorname{Exc} 2 \\
\text { conc } \\
(\mathrm{mM})\end{array}$ & Exc 3 & $\begin{array}{c}\text { Exc } 3 \\
\text { conc } \\
(\mathrm{mM})\end{array}$ & pH & $\begin{array}{c}\eta \\
(\mathbf{c P})\end{array}$ & $\begin{array}{c}\boldsymbol{\eta}_{0} \\
(\mathbf{c P})\end{array}$ & $\begin{array}{c}\eta_{\text {inh }} \\
(\mathrm{mL} / \mathrm{g})\end{array}$ & $\begin{array}{l}\text { Turbidity } \\
\left(\mathrm{AU}^{*} \mathrm{~cm}^{-1}\right)\end{array}$ & $\begin{array}{c}\text { DF } \\
\text { time } \\
\text { (min) }\end{array}$ & $\begin{array}{c}\mathbf{U F} \\
\text { time } \\
(\mathbf{m i n})\end{array}$ \\
\hline $261 \pm 5.6$ & His & 30 & $\mathrm{HCl}$ & 17 & Tre & 220 & 6.1 & 329 & 1.05 & 22.0 & 0.421 & 90 & 75 \\
\hline $267 \pm 2.0$ & His & 322 & CitrA & 79 & --- & -- & 5.9 & 69 & 1.10 & 15.5 & 0.427 & 73 & 50 \\
\hline $270 \pm 0.5$ & His & 322 & CitrA & 79 & -- & -- & 6.0 & 54 & 1.10 & 14.5 & 0.409 & 30 & 42 \\
\hline $265 \pm 6.1$ & His & 322 & CitrA & 79 & Tre & 106 & 5.8 & 85 & 1.11 & 16.4 & 0.341 & 73 & 75 \\
\hline $242 \pm 0.2$ & His & 322 & CitrA & 79 & Tre & 106 & 6.0 & 48 & 1.11 & 15.6 & 0.405 & 30 & 42 \\
\hline
\end{tabular}


Table 4. Different TFF buffer exchange conditions for Replicates $1-4$ of the 40:50:17 mg/mL Tre:His:CitrA solution (Figure 2) and resulting turbidity. The thawed mAb stock was additionally sterile-filtered and degassed before diafiltration in Replicate 4 . The $0.5 \mathrm{~mm}$ fiber ID modules have a higher water flux than the $1.0 \mathrm{~mm}$ fiber ID modules, as seen in Fig. S10, which may contribute to the higher permeate flux observed in the high-shear experiments (Replicates 3 and 4). The turbidity of the buffer-exchanged solution was measured as the absorbance at $350 \mathrm{~nm}$ for a $1 \mathrm{~cm}$ path length and corrected for the absorbance of the protein-free buffer.

\begin{tabular}{|c|c|c|c|c|c|c|c|c|}
\hline Sample & $\begin{array}{c}\text { mAb } \\
\text { conc } \\
\text { during } \\
\text { buffer } \\
\text { exchange } \\
(\mathbf{m g} / \mathbf{m L})\end{array}$ & $\begin{array}{c}\text { TMP } \\
(\mathbf{b a r})\end{array}$ & $\begin{array}{c}\text { Filter } \\
\text { wall } \\
\text { shear } \\
\text { rate } \\
\left.\mathbf{s}^{-1}\right)\end{array}$ & $\begin{array}{c}\text { Hollow } \\
\mathbf{f i b e r} \\
\mathbf{I D} \\
(\mathbf{m m})\end{array}$ & $\begin{array}{c}\text { Membrane } \\
\mathbf{m A b} \\
\mathbf{l o a d i n g} \\
\mathbf{( g / \mathbf { m } ^ { 2 } )}\end{array}$ & $\begin{array}{c}\text { Tubing } \\
\text { ID }(\mathbf{m m})\end{array}$ & $\begin{array}{c}\text { Tubing } \\
\text { wall shear } \\
\text { rate } \\
\left(\mathbf{s}^{-1}\right)\end{array}$ & $\begin{array}{c}\text { Turbidity } \\
\text { pre-sterile } \\
\text { filtration } \\
\left(\mathbf{A} \mathbf{U}^{*} \mathbf{c m}^{-\mathbf{1}}\right)\end{array}$ \\
\hline Replicate 1 & 22 & 0.8 & 1405 & 1.0 & 390 & 1.6 & 4145 & 0.380 \\
\hline Replicate 4 & 20 & 0.8 & 8200 & 0.5 & 407 & 3.1 & 1254 & 0.131 \\
\hline Replicate 2 & 65 & 0.8 & 1405 & 1.0 & 390 & 1.6 & 4145 & 0.953 \\
\hline Replicate 3 & 66 & 0.8 & 8250 & 0.5 & 254 & 3.1 & 1254 & 1.771 \\
\hline
\end{tabular}


Table 5. Membrane fouling and protein adsorption after ultrafiltration by TFF. The membrane normalized water permeability (NWP) was measured at room temperature $\left(20^{\circ} \mathrm{C}\right)$. The mass of mAb recovered during the filter wash was determined from the $\mathrm{mAb}$ concentration in the wash water after recirculation. The small calculated negative mAb mass losses for some formulations may be due to minor experimental error in concentration measurements.

\begin{tabular}{|c|c|c|c|c|c|c|c|c|}
\hline Formulation & $\begin{array}{c}\text { Pre-UF } \\
\text { NWP } \\
\text { (LMH/ } \\
\text { bar) }\end{array}$ & $\begin{array}{l}\text { Post- } \\
\text { UF } \\
\text { NWP } \\
\text { (LMH } \\
\text { /bar) }\end{array}$ & $\begin{array}{l}\% \text { NWP } \\
\text { reduction } \\
\text { post- } \\
\text { fouling }\end{array}$ & $\begin{array}{c}\text { mAb } \\
\text { recovered } \\
\text { from } \\
\text { filter } \\
\text { wash } \\
\text { (mg) }\end{array}$ & $\begin{array}{c}\text { mAb } \\
\text { recovered } \\
\text { in solution } \\
\quad(\mathbf{m g})\end{array}$ & $\begin{array}{c}\text { mAb } \\
\text { in UF } \\
\text { feed } \\
\text { stock } \\
(\mathbf{m g})\end{array}$ & $\begin{array}{c}\text { mAb } \\
\text { lost to } \\
\text { adsorpt. } \\
\text { on filter } \\
\text { (mg) }\end{array}$ & $\begin{array}{c}\% \text { mAb } \\
\text { lost to } \\
\text { irrevers. } \\
\text { adsorption } \\
\text { on filter }\end{array}$ \\
\hline \multicolumn{9}{|c|}{ Low co-solute solutions } \\
\hline $\begin{array}{c}\text { Freezing } \\
\text { buffer }\end{array}$ & 298 & 80 & 62 & 758 & 1565 & 2624 & 301 & 11.5 \\
\hline DI water & 213 & 78 & 63 & 775 & 1480 & 2232 & -23 & -1.0 \\
\hline \multicolumn{9}{|c|}{ High co-solute solutions } \\
\hline $\begin{array}{c}\text { 40:50:17 } \\
\text { mg/mL } \\
\text { Tre:His:CitrA } \\
\text { (Replicate 4) }\end{array}$ & 232 & 166 & 29 & 674 & 3080 & 4121 & 367 & 8.9 \\
\hline $\begin{array}{c}\text { 40:50:17 } \\
\text { mg/mL } \\
\text { Tre:His:CitrA } \\
\text { (Replicate 1) }\end{array}$ & 221 & 141 & 36 & 522 & 1445 & 2131 & 164 & 7.7 \\
\hline $\begin{array}{c}\text { 50:50:12 } \\
\text { mg/mL } \\
\text { Tre:His:PhosA }\end{array}$ & 289 & 107 & 63 & 600 & 1745 & 2327 & -18 & -0.8 \\
\hline $\begin{array}{c}\text { 50:17:7 } \\
\text { mg/mL } \\
\text { Tre:Im:HCl }\end{array}$ & 277 & 138 & 50 & 707 & 1503 & 2284 & 74 & 3.2 \\
\hline $\begin{array}{c}\text { 50:17:10 } \\
\text { mg/mL } \\
\text { Tre:Im:CitrA }\end{array}$ & 267 & 57 & 79 & 573 & 1769 & 2606 & 264 & 10.1 \\
\hline
\end{tabular}


Table 6. Mass transfer coefficient $\boldsymbol{k}_{\boldsymbol{c}}$ and gel point $\boldsymbol{c}_{\boldsymbol{g}}$ from linear fit of flux decay profile. The slope and y-intercept were obtained from linear fits of the flux decay profiles in Fig. $4 \mathrm{a}$ and used to calculate $c_{g}$ and $k_{c}$ (Eq. 4)

\begin{tabular}{|l|c|c|c|c|}
\hline \multicolumn{1}{|c|}{ Sample } & Slope & y-intercept & $\boldsymbol{c}_{\boldsymbol{g}}(\mathbf{m g} / \mathbf{m l})$ & $\boldsymbol{k}_{\boldsymbol{c}}(\mathbf{c m} / \mathbf{s})^{*} \mathbf{1 0}^{\mathbf{5}}$ \\
\hline Freezing buffer & -3.617 & 20.0 & 254 & 10.0 \\
\hline DI water & -4.952 & 27.5 & 258 & 13.8 \\
\hline Tre-His-Citr, Rep 1 & -2.739 & 15.9 & 335 & 7.6 \\
\hline Tre-His-Citr, Rep 4 & -2.696 & 15.6 & 330 & 7.5 \\
\hline Tre-His-Phos & -2.401 & 14.2 & 365 & 6.7 \\
\hline Tre-Im-HCl & -2.591 & 14.9 & 315 & 7.2 \\
\hline Tre-Im-CitrA & -2.334 & 13.6 & 344 & 6.5 \\
\hline
\end{tabular}


Table 7. Turbidity $(0.2 \mathrm{~cm}$ path length), turbidity/concentration (c) and viscosity $(\eta)$ before and after syringe sterile filtration of Replicate 4 of the 40:50:17 mg/mL Tre:His:CitrA solution. The turbidity was corrected for the absorbance of the protein-free buffer.

\begin{tabular}{|c|c|c|c|c|c|c|}
\hline Sample ID & $\begin{array}{c}\mathrm{mAb} \text { conc } \\
(\mathrm{mg} / \mathrm{mL})\end{array}$ & $\begin{array}{c}\eta \\
(\mathrm{cP})\end{array}$ & $\eta_{\text {inh }}(\mathrm{mL} / \mathrm{g})$ & $\begin{array}{c}\text { Absorbance at } \\
350 \mathrm{~nm}(\mathrm{AU})\end{array}$ & $\begin{array}{c}\text { Turbidity at } \\
350 \mathrm{~nm} \\
\left(\mathrm{AU}^{*} \mathrm{~cm}^{-1}\right)\end{array}$ & $\begin{array}{c}\text { Turbidity/c } \\
\left(\mathrm{AU}^{*} \mathrm{~mL}^{*} \mathrm{mg}^{-1} \mathrm{~cm}^{-1}\right)\end{array}$ \\
\hline $\begin{array}{c}\text { Before } \\
\text { filtration }\end{array}$ & 307 & 138 & 15.7 & 0.174 & 0.868 & 0.0028 \\
\hline $\begin{array}{c}\text { After } \\
\text { filtration }\end{array}$ & 223 & 22 & 13.4 & 0.083 & 0.414 & 0.0019 \\
\hline
\end{tabular}


Table 8. Initial stability of mAb solutions by SEC. Samples were analyzed by SEC within two weeks of when the samples were manufactured except for the Tre:Im:CitrA solution, which was measured seven months after the solution was manufactured. All samples were stored at $4{ }^{\circ} \mathrm{C}$ between manufacture and SEC measurements. The \% monomer was determined from the ratio of the monomer to the combined monomer and aggregate peak areas, whereas the monomer recovery was determined from the ratio of the monomer peak areas for the post-ultrafiltration sample and the $\mathrm{mAb}$ control (unstressed $130 \mathrm{mg} / \mathrm{mL} \mathrm{mAb}$ starting material in freezing buffer).

\begin{tabular}{|l|c|c|}
\hline Formulation & \% Monomer & $\begin{array}{c}\text { Monomer } \\
\text { recovery (\%) }\end{array}$ \\
\hline \multicolumn{2}{|c|}{ Concentrated solution from TFF } & 100.0 \\
\hline mAb control (130 mg/mL) & 99.7 & 93.6 \\
\hline 40:50:17 mg/mL Tre:His:CitrA, pH 6 (280 mg/mL) & 99.5 & 88.9 \\
\hline 40:50:17 mg/mL Tre:His:CitrA, pH 6 (240 mg/mL) & 99.9 & 86.2 \\
\hline 50:50:12 mg/mL Tre:His:PhosA, pH 6 $(250 \mathrm{mg} / \mathrm{mL})$ & 99.9 & 91.8 \\
\hline 50:17:7 mg/mL Tre:Im:HCl, pH 6.3 (260 mg/mL) & 99.0 & 89.2 \\
\hline 50:17:10 mg/mL Tre:Im:CitrA, pH 7 (250 mg/mL) & $97.4^{\mathrm{a}}$ & $\mathbf{8 3 . 7}$ \\
\hline Freezing buffer (235 mg/mL) & $99.5^{\mathrm{b}}$ & $\mathbf{6 2 . 6}$ \\
\hline DI water (245 mg/mL) & $99.4^{\mathrm{b}}$ & \\
\hline \multicolumn{2}{|c|}{ Dilution of 40:50:17 mg/mL Tre:His:CitrA solution (original $280 \mathrm{mg} / \mathrm{mL})$} \\
\hline 256 mg/mL dilution & 99.5 & 90.8 \\
\hline 237 mg/mL dilution & 99.5 & 95.8 \\
\hline $183 \mathrm{mg} / \mathrm{mL}$ dilution & 99.5 & 97.2 \\
\hline
\end{tabular}

a. After 7 months storage at $4^{\circ} \mathrm{C}$

b. Visible $\sim 1 \mathrm{~mm}$ gel-like clumps (aggregates) observed upon dilution to $2 \mathrm{mg} / \mathrm{mL}$ in mobile phase; removed by sterile filtration prior to SEC analysis 
Table 9. Viscosity $(\eta)$, inherent viscosity $\left(\eta_{i n h}\right)$ and SEC stability of Replicate 4 of the 40:50:17 $\mathrm{mg} / \mathrm{mL}$ Tre:His:CitrA solution after up to 4-weeks of storage at $-40^{\circ} \mathrm{C}, 4^{\circ} \mathrm{C}$ and $37^{\circ} \mathrm{C}$. No 56-day sample at $37^{\circ} \mathrm{C}$ was available due to evaporative losses which rendered the sample too concentrated and viscous even for concentration measurements. The $\%$ monomer was determined from the ratio of the monomer to the combined monomer and aggregate peak areas, whereas the monomer recovery was determined from the ratio of the monomer peak areas for mAb solution before and after accelerated storage.

\begin{tabular}{|c|c|c|c|c|c|c|c|}
\hline $\begin{array}{c}\text { Time } \\
(\mathbf{d a y s})\end{array}$ & $\begin{array}{c}\text { Storage } \\
\text { temp } \\
\left({ }^{\circ} \mathbf{C}\right)\end{array}$ & $\begin{array}{c}\text { mAb conc } \\
(\mathbf{m g} / \mathbf{m L})\end{array}$ & $\begin{array}{c}\boldsymbol{\eta} \\
(\mathbf{c P})\end{array}$ & $\begin{array}{c}\boldsymbol{\eta}_{\text {inh }} \\
(\mathbf{m L} \mathbf{g})\end{array}$ & $\mathbf{p H}$ & $\begin{array}{c}\text { \% } \\
\text { monomer } \\
\text { by SEC }\end{array}$ & $\begin{array}{c}\text { Monomer } \\
\text { recovery } \\
(\mathbf{\%})\end{array}$ \\
\hline 4 & -40 & $278 \pm 5.3$ & $92 \pm 3.7$ & 15.9 & 5.99 & 99.6 & 93.3 \\
\hline 4 & 4 & $274 \pm 6.6$ & $88 \pm 5.5$ & 16.0 & 5.96 & 99.5 & 92.2 \\
\hline 4 & 37 & $330 \pm 2.7$ & $297 \pm 3.9$ & 16.9 & 5.95 & 99.4 & 91.8 \\
\hline 7 & -40 & $263 \pm 2.7$ & $82 \pm 3.7$ & 16.4 & 5.98 & 99.5 & 97.7 \\
\hline 7 & 4 & $266 \pm 10.0$ & $88 \pm 2.3$ & 16.4 & 5.97 & 99.6 & 84.3 \\
\hline 7 & 37 & $260 \pm 10.9$ & $77 \pm 0.6$ & 16.3 & 5.97 & 99.4 & 98.3 \\
\hline 14 & -40 & $287 \pm 5.1$ & $101 \pm 0.9$ & 15.7 & 5.95 & 99.5 & $103.9^{\mathrm{a}}$ \\
\hline 14 & 4 & $288 \pm 3.4$ & $98 \pm 5.7$ & 15.6 & 5.98 & 99.5 & 96.7 \\
\hline 14 & 37 & $454 \pm 34.8$ & $---{ }^{\mathrm{b}}$ & $--{ }^{\mathrm{b}}$ & $--{ }^{\mathrm{b}}$ & 99.2 & 96.3 \\
\hline 28 & -40 & $291 \pm 3.5$ & $132 \pm 0.8$ & 16.4 & 5.92 & 99.5 & 93.9 \\
\hline 28 & 4 & $302 \pm 6.4$ & $133 \pm 1.9$ & 15.8 & 5.94 & 99.5 & 93.8 \\
\hline 28 & 37 & $299 \pm 4.2$ & $86 \pm 2.4$ & 14.5 & 5.99 & 99.2 & 90.7 \\
\hline 56 & -40 & $279 \pm 1.4$ & $106 \pm 2.6$ & 16.3 & 5.95 & 99.4 & 85.0 \\
\hline 56 & 4 & $272 \pm 0.5$ & $114 \pm 6.1$ & 17.1 & 5.96 & $-{ }^{\mathrm{c}}$ & $-{ }^{\mathrm{c}}$ \\
\hline
\end{tabular}

a. Monomer recovery greater than $100 \%$ likely due to experimental error resulting in SEC sample being slightly more concentrated than $2 \mathrm{mg} / \mathrm{mL}$

b. Sample became too concentrated and viscous to characterize by rheometry

c. Remaining sample volume after viscometry and concentration measurements was insufficient for SEC measurements 
[1] P.J. Sinko, A. Martin, Martin's Physical Pharmacy and Pharmaceutical Sciences, 5 ed., Lippincott Williams \& Wilkins, Philadelphia, 2006.

[2] T.M. Scherer, J. Liu, S.J. Shire, Intermolecular Interactions of IgG1 Monoclonal Antibodies at High Concentrations Characterized by Light Scattering, J. Phys. Chem., 114 (2010) 12948-12957.

[3] S.J. Shire, Z. Shahrokh, J. Liu, Challenges in the Development of High Protein Concentration Formulations, J. Pharm. Sci., 93 (2004) 1390-1402.

[4] J. Liu, M.D.H. Nguyen, J.D. Andya, S.J. Shire, Reversible Self-Association Increases the Viscosity of a Concentrated Monoclonal Antibody in Aqueous Solution, J. Pharm. Sci., 94 (2005) 1928-1940.

[5] C. Srinivasan, A.K. Weight, T. Bussemer, A.M. Klibanov, Non-Aqueous Suspensions of Antibodies are Much Less Viscous Than Equally Concentrated Aqueous Solutions, Pharmaceutical research, (2013). [6] E. Rosenberg, S. Hepbildikler, W. Kuhne, G. Winter, Ultrafiltration concentration of monoclonal antibody solutions: Development of an optimized method minimizing aggregation, Journal of Membrane Science, 342 (2009) 50-59.

[7] M.E.M. Cromwell, E. Hilario, F. Jacobson, Protein aggregation and bioprocessing, Aaps J., 8 (2006) E572-E579.

[8] K. Ahrer, A. Buchacher, G. Iberer, A. Jungbauer, Effects of ultra-/diafiltration conditions on present aggregates in human immunoglobulin G preparations, Journal of Membrane Science, 274 (2006) 108115.

[9] G.R. Bolton, A.W. Boesch, J. Basha, D.P. LaCasse, B.D. Kelley, H. Acharya, Effect of protein and solution properties on the donnan effect during the ultrafiltration of proteins, Biotechnol Prog, 27 (2011) 140-152.

[10] M. Teeters, D. Bezila, T. Benner, P. Alfonso, P. Alred, Predicting diafiltration solution compositions for final ultrafiltration/diafiltration steps of monoclonal antibodies, Biotechnology and Bioengineering, 108 (2011) 1338-1346.

[11] S. Kanai, J. Liu, T.W. Patapoff, S.J. Shire, Reversible Self-Association of a Concentrated Monoclonal Antibody Solution Mediated by Fab-Fab Interaction That Impacts Solution Viscosity, J Pharm Sci, 97 (2008) 4219-4227.

[12] E. Binabaji, J. Ma, S. Rao, A.L. Zydney, Theoretical analysis of the ultrafiltration behavior of highly concentrated protein solutions, Journal of Membrane Science, (2015) JMS151044.

[13] C. Casey, T. Gallos, Y. Alekseev, E. Ayturk, S. Pearl, Protein concentration with single-pass tangential flow filtration (SPTFF), Journal of Membrane Science, 384 (2011) 82-88.

[14] R. van Reis, A. Zydney, Bioprocess membrane technology, Journal of Membrane Science, 297 (2007) 16-50.

[15] B. Marcos, C. Moresoli, J. Skorepova, B. Vaughan, CFD modeling of a transient hollow fiber ultrafiltration system for protein concentration, Journal of Membrane Science, 337 (2009) 136-144.

[16] S.R. Bellara, Z.F. Cui, A Maxwell-Stefan approach to modelling the cross-flow ultrafiltration of protein solutions in tubular membranes, Chemical Engineering Science, 53 (1998) 2153-2166.

[17] D.M. Kanani, R. Ghosh, A constant flux based mathematical model for predicting permeate flux decline in constant pressure protein ultrafiltration, Journal of Membrane Science, 290 (2007) 207-215. [18] G. Belfort, R.H. Davis, A.L. Zydney, The behavior of suspensions and macromolecular solutions in crossflow microfiltration, Journal of Membrane Science, 96 (1994) 1-58.

[19] J. Jaspe, S.J. Hagen, Do Protein Molecules Unfold in a Simple Shear Flow?, Biophysical journal, 91 (2006) 3415-3424.

[20] D.J. Callahan, B. Stanley, Y.L. Li, Control of Protein Particle Formation During Ultrafiltration/Diafiltration Through Interfacial Protection, Journal of pharmaceutical sciences, 103 (2014) 862-869. 
[21] J.S. Bee, J.L. Stevenson, B. Mehta, J. Svitel, J. Pollastrini, R. Platz, E. Freund, J.F. Carpenter, T.W. Randolph, Response of a concentrated monoclonal antibody formulation to high shear, Biotechnology and Bioengineering, 103 (2009) 936-943.

[22] J. Dizon-Maspat, J. Bourret, A. D'Agostini, F. Li, Single pass tangential flow filtration to debottleneck downstream processing for therapeutic antibody production, Biotechnology and Bioengineering, 109 (2012) 962-970.

[23] A. Eppler, M. Weigandt, S. Schulze, A. Hanefeld, H. Bunjes, Comparison of different protein concentration techniques within preformulation development, International Journal of Pharmaceutics, 421 (2011) 120-129.

[24] SpectrumLabs, Modified PES Fiber Modules, in, 2014.

[25] P.D. Ross, A.P. Minton, HARD QUASI-SPHERICAL MODEL FOR VISCOSITY OF HEMOGLOBIN SOLUTIONS, Biochemical and Biophysical Research Communications, 76 (1977) 971-976.

[26] V. Burckbuchler, G. Mekhloufi, A.P. Giteau, J.L. Grossiord, S. Huille, F. Agnely, Rheological and syringeability properties of highly concentrated human polyclonal immunoglobulin solutions, European Journal of Pharmaceutics and Biopharmaceutics, 76 (2010) 351-356.

[27] S. Yadav, J. Liu, S.J. Shire, D.S. Kalonia, Specific Interactions in High Concentration Antibody Solutions Resulting in High Viscosity, J Pharm Sci, 99 (2010) 1152-1168.

[28] Brian D. Connolly, C. Petry, S. Yadav, B. Demeule, N. Ciaccio, Jamie M.R. Moore, Steven J. Shire, Yatin R. Gokarn, Weak Interactions Govern the Viscosity of Concentrated Antibody Solutions: HighThroughput Analysis Using the Diffusion Interaction Parameter, Biophysical journal, 103 (2012) 69-78. [29] S. Yadav, S.J. Shire, D.S. Kalonia, Factors Affecting the Viscosity in High Concentration Solutions of Different Monoclonal Antibodies, Journal of pharmaceutical sciences, 99 (2010) 4812-4829.

[30] S. Yadav, T.M. Laue, D.S. Kalonia, S.N. Singh, S.J. Shire, The Influence of Charge Distribution on SelfAssociation and Viscosity Behavior of Monoclonal Antibody Solutions, Molecular Pharmaceutics, 9 (2012) 791-802.

[31] C.J. Roberts, M.A. Blanco, Role of Anisotropic Interactions for Proteins and Patchy Nano-particles, The Journal of Physical Chemistry B, (2014).

[32] Eric J. Yearley, Paul D. Godfrin, T. Perevozchikova, H. Zhang, P. Falus, L. Porcar, M. Nagao, Joseph E. Curtis, P. Gawande, R. Taing, Isidro E. Zarraga, Norman J. Wagner, Y. Liu, Observation of Small Cluster Formation in Concentrated Monoclonal Antibody Solutions and Its Implications to Solution Viscosity, Biophysical journal, 106 (2014) 1763-1770.

[33] R. Chari, K. Jerath, A.V. Badkar, D.S. Kalonia, Long- and Short-Range Electrostatic Interactions Affect the Rheology of Highly Concentrated Antibody Solutions, Pharm. Res., 26 (2009) 2607-2618.

[34] T.P. Moody, J.S. Kingsbury, J.A. Durant, T.J. Wilson, S.F. Chase, T.M. Laue, Valence and anion binding of bovine ribonuclease A between pH 6 and 8, Analytical biochemistry, 336 (2005) 243-252.

[35] A. Salis, M. Bostrom, L. Medda, F. Cugia, B. Barse, D.F. Parsons, B.W. Ninham, M. Monduzzi, Measurements and theoretical interpretation of points of zero charge/potential of BSA protein, Langmuir 27 (2011) 11597-11604.

[36] W. Du, A.M. Klibanov, Hydrophobic salts markedly diminish viscosity of concentrated protein solutions, Biotechnology and Bioengineering, 108 (2011) 632-636.

[37] Z. Guo, A. Chen, R. Nassar, B. Helk, C. Mueller, Y. Tang, K. Gupta, A. Klibanov, Structure-Activity Relationship for Hydrophobic Salts as Viscosity-Lowering Excipients for Concentrated Solutions of Monoclonal Antibodies, Pharmaceutical research, 29 (2012) 3102-3109.

[38] P. Kheddo, M. Tracka, J. Armer, R.J. Dearman, S. Uddin, C.F. van der Walle, A.P. Golovanov, The effect of arginine glutamate on the stability of monoclonal antibodies in solution, International journal of pharmaceutics, 473 (2014) 126-133. 
[39] M. Fukuda, D. Kameoka, T. Torizawa, S. Saitoh, M. Yasutake, Y. Imaeda, A. Koga, A. Mizutani, Thermodynamic and Fluorescence Analyses to Determine Mechanisms of IgG1 Stabilization and Destabilization by Arginine, Pharmaceutical research, 31 (2014) 992-1001.

[40] M. Fukuda, C. Moriyama, T. Yamazaki, Y. Imaeda, A. Koga, Quantitative Correlation between Viscosity of Concentrated MAb Solutions and Particle Size Parameters Obtained from Small-Angle X-ray Scattering, Pharmaceutical research, (2015) 1-10.

[41] N. Inoue, E. Takai, T. Arakawa, K. Shiraki, Specific Decrease in Solution Viscosity of Antibodies by Arginine for Therapeutic Formulations, Molecular Pharmaceutics, 11 (2014) 1889-1896.

[42] N. Inoue, E. Takai, T. Arakawa, K. Shiraki, Arginine and lysine reduce the high viscosity of serum albumin solutions for pharmaceutical injection, Journal of Bioscience and Bioengineering, 117 (2014) 539-543.

[43] E. Binabaji, J. Ma, A. Zydney, Intermolecular Interactions and the Viscosity of Highly Concentrated Monoclonal Antibody Solutions, Pharmaceutical research, 32 (2015) 3102-3109.

[44] B. Chen, R. Bautista, K. Yu, G.A. Zapata, M.G. Mulkerrin, S.M. Chamow, Influence of histidine on the stability and physical properties of a fully human antibody in aqueous and solid forms, Pharmaceutical research, 20 (2003) 1952-1960.

[45] T.M. Scherer, The Role of Cosolute-Protein Interactions in the Dissociation of Monoclonal Antibody Clusters, The Journal of Physical Chemistry B, (2015).

[46] J. Heyda, P.E. Mason, P. Jungwirth, Attractive Interactions between Side Chains of HistidineHistidine and Histidine-Arginine-Based Cationic Dipeptides in Water, The Journal of Physical Chemistry B, 114 (2010) 8744-8749.

[47] K.P. Johnston, J.A. Maynard, T.M. Truskett, A.U. Borwankar, M.A. Miller, B.K. Wilson, A.K. Dinin, T.A. Khan, K.J. Kaczorowski, Concentrated Dispersions of Equilibrium Protein Nanoclusters that Reversibly Dissociate into Active Monomers, ACS Nano, 6 (2012) 1357-1369.

[48] A.U. Borwankar, A.K. Dinin, J.R. Laber, A. Twu, B.K. Wilson, J.A. Maynard, T.M. Truskett, K.P. Johnston, Tunable equilibrium nanocluster dispersions at high protein concentrations, Soft Matter, 9 (2013) 1766.

[49] H.N.W. Lekkerkerker, R. Tuinier, Colloids and the Depletion Interaction, 2011 ed., Springer, 2011. [50] S. Asakura, F. Oosawa, Interaction between particles suspended in solutions of macromolecules, Journal of Polymer Science, 33 (1958) 183-192.

[51] V.K. Shen, J.K. Cheung, J.R. Errington, T.M. Truskett, Coarse-Grained Strategy for Modeling Protein Stability in Concentrated Solutions II: Phase Behavior, Biophysical journal, 90 (2006) 1949-1960.

[52] V.K. Shen, J.K. Cheung, J.R. Errington, T.M. Truskett, Insights into crowding effects on protein stability from a coarse-grained model, J Biomech Eng, 131 (2009) 071002.

[53] C.A. Schneider, W.S. Rasband, K.W. Eliceiri, NIH Image to ImageJ: 25 years of image analysis, Nat Meth, 9 (2012) 671-675.

[54] J. Jezek, M. Rides, B. Derham, J. Moore, E. Cerasoli, R. Simler, B. Perez-Ramirez, Viscosity of concentrated therapeutic protein compositions, Adv Drug Deliv Rev, 63 (2011) 1107-1117.

[55] P.C. Heimenz, R. Rajagopalan, Principles of Colloid and Surface Chemistry, 3rd ed., Marcel Dekker, Inc., New York, 1997.

[56] K. Monkos, B. Turczynski, A comparative study on viscosity of human, bovine and pig IgG immunoglobulins in aqueous solutions, International Journal of Biological Macromolecules, 26 (1999) 155-159.

[57] S.S. Sablani, M.F.A. Goosen, R. Al-Belushi, M. Wilf, Concentration polarization in ultrafiltration and reverse osmosis: a critical review, Desalination, 141 (2001) 269-289.

[58] A.R. Cooper, Ultrafiltration membranes and applications, in: W.J. Bailey, J.P. Berry, A.T. DiBenedetto, C.A.J. Hoeve, Y. Ishida, F.E. Karasz, O. Solomon (Eds.) Polymer Science and Technology, Plenum Press, New York, 1979, pp. 707. 
[59] W. McCabe, J. Smith, P. Harriot, Unit Operations of Chemical Engineering, 7th ed., McGraw-Hill Education, Columbus, 2004.

[60] A. Subramani, S. Kim, E.M.V. Hoek, Pressure, flow, and concentration profiles in open and spacerfilled membrane channels, Journal of Membrane Science, 277 (2006) 7-17.

[61] L. Palacio, C.-C. Ho, A.L. Zydney, Application of a pore-blockage-Cake-filtration model to protein fouling during microfiltration, Biotechnology and Bioengineering, 79 (2002) 260-270.

[62] M. Grimaldo, F. Roosen-Runge, F. Zhang, T. Seydel, F. Schreiber, Diffusion and Dynamics of $\gamma^{-}$ Globulin in Crowded Aqueous Solutions, The Journal of Physical Chemistry B, 118 (2014) 7203-7209. [63] Jai A. Pathak, Rumi R. Sologuren, R. Narwal, Do Clustering Monoclonal Antibody Solutions Really Have a Concentration Dependence of Viscosity?, Biophysical journal, 104 (2013) 913-923.

[64] W.G. Lilyestrom, S. Yadav, S.J. Shire, T.M. Scherer, Monoclonal Antibody Self-Association, Cluster Formation, and Rheology at High Concentrations, The Journal of Physical Chemistry B, 117 (2013) 63736384.

[65] E.J. Yearley, I.E. Zarraga, S.J. Shire, T.M. Scherer, Y. Gokarn, N.J. Wagner, Y. Liu, Small-Angle Neutron Scattering Characterization of Monoclonal Antibody Conformations and Interactions at High Concentrations, Biophysical journal, 105 (2013) 720-731.

[66] S. Yadav, A. Sreedhara, S. Kanai, J. Liu, S. Lien, H. Lowman, D. Kalonia, S. Shire, Establishing a Link Between Amino Acid Sequences and Self-Associating and Viscoelastic Behavior of Two Closely Related Monoclonal Antibodies, Pharmaceutical research, 28 (2011) 1750-1764.

[67] A.R. Karow, S. Bahrenburg, P. Garidel, Buffer capacity of biologics--from buffer salts to buffering by antibodies, Biotechnol Prog, 29 (2013) 480-492.

[68] F. Miao, A. Velayudhan, E. DiBella, J. Shervin, M. Felo, M. Teeters, P. Alred, Theoretical analysis of excipient concentrations during the final ultrafiltration/diafiltration step of therapeutic antibody, Biotechnol Prog, 25 (2009) 964-972.

[69] B.A. Salinas, H.A. Sathish, S.M. Bishop, N. Harn, J.F. Carpenter, T.W. Randolph, Understanding and Modulating Opalescence and Viscosity in a Monoclonal Antibody Formulation, J Pharm Sci, 99 (2010) 8292.

[70] F. Péter, P. Lionel, F. Emiliano, C. Wei-Ren, F. Antonio, H. Kunlun, B. Piero, L. Yun, Distinguishing the monomer to cluster phase transition in concentrated lysozyme solutions by studying the temperature dependence of the short-time dynamics, Journal of Physics: Condensed Matter, 24 (2012) 064114. [71] L. Porcar, P. Falus, W.-R. Chen, A. Faraone, E. Fratini, K. Hong, P. Baglioni, Y. Liu, Formation of the Dynamic Clusters in Concentrated Lysozyme Protein Solutions, The Journal of Physical Chemistry Letters, 1 (2009) 126-129.

[72] Y. Liu, L. Porcar, J. Chen, W.-R. Chen, P. Falus, A. Faraone, E. Fratini, K. Hong, P. Baglioni, Lysozyme Protein Solution with an Intermediate Range Order Structure, The Journal of Physical Chemistry B, 115 (2010) 7238-7247.

[73] B. Lonetti, E. Fratini, S.H. Chen, P. Baglioni, Viscoelastic and small angle neutron scattering studies of concentrated protein solutions, Physical Chemistry Chemical Physics, 6 (2004) 1388-1395.

[74] D. Soraruf, F. Roosen-Runge, M. Grimaldo, F. Zanini, R. Schweins, T. Seydel, F. Zhang, R. Roth, M. Oettel, F. Schreiber, Protein cluster formation in aqueous solution in the presence of multivalent metal ions - a light scattering study, Soft Matter, 10 (2014) 894-902.

[75] W.C. Pan, P.G. Vekilov, V. Lubchenko, Origin of Anomalous Mesoscopic Phases in Protein Solutions, J. Phys. Chem. B, 114 (2010) 7620-7630.

[76] Y. Li, V. Lubchenko, P.G. Vekilov, The use of dynamic light scattering and Brownian microscopy to characterize protein aggregation, Review of Scientific Instruments, 82 (2011) -.

[77] A. Chaudhri, I.E. Zarraga, T.J. Kamerzell, J.P. Brandt, T.W. Patapoff, S.J. Shire, G.A. Voth, CoarseGrained Modeling of the Self-Association of Therapeutic Monoclonal Antibodies, The Journal of Physical Chemistry B, 116 (2012) 8045-8057. 
[78] P.D. Godfrin, R. Castañeda-Priego, Y. Liu, N.J. Wagner, Intermediate range order and structure in colloidal dispersions with competing interactions, The Journal of Chemical Physics, 139 (2013) -. [79] P.D. Godfrin, N.E. Valadez-Perez, R. Castaneda-Priego, N.J. Wagner, Y. Liu, Generalized phase behavior of cluster formation in colloidal dispersions with competing interactions, Soft Matter, (2014). [80] A. Chaudhri, I.E. Zarraga, S. Yadav, T.W. Patapoff, S.J. Shire, G.A. Voth, The Role of Amino Acid Sequence in the Self-Association of Therapeutic Monoclonal Antibodies: Insights from Coarse-Grained Modeling, The Journal of Physical Chemistry B, 117 (2013) 1269-1279.

[81] M.M. Castellanos, J.A. Pathak, R.H. Colby, Both protein adsorption and aggregation contribute to shear yielding and viscosity increase in protein solutions, Soft Matter, 10 (2014) 122-131.

[82] I.E. Zarraga, R. Taing, J. Zarzar, J. Luoma, J. Hsiung, A. Patel, F.J. Lim, High shear rheology and anisotropy in concentrated solutions of monoclonal antibodies, Journal of pharmaceutical sciences, 102 (2013) 2538-2549.

[83] A. Allmendinger, S. Fischer, J. Huwyler, H.-C. Mahler, E. Schwarb, I.E. Zarraga, R. Mueller, Rheological characterization and injection forces of concentrated protein formulations: An alternative predictive model for non-Newtonian solutions, European Journal of Pharmaceutics and Biopharmaceutics, 87 (2014) 318-328.

[84] S. Yadav, S.J. Shire, D.S. Kalonia, Viscosity behavior of high-concentration monoclonal antibody solutions: Correlation with interaction parameter and electroviscous effects, Journal of pharmaceutical sciences, 101 (2012) 998-1011.

[85] J.D. Schmit, F. He, S. Mishra, R.R. Ketchem, C.E. Woods, B.A. Kerwin, Entanglement Model of Antibody Viscosity, The Journal of Physical Chemistry B, 118 (2014) 5044-5049.

[86] K. Štulík, V. Pacáková, M. Tichá, Some potentialities and drawbacks of contemporary size-exclusion chromatography, Journal of Biochemical and Biophysical Methods, 56 (2003) 1-13.

[87] D. Shukla, B.L. Trout, Interaction of Arginine with Proteins and the Mechanism by Which It Inhibits Aggregation, The Journal of Physical Chemistry B, 114 (2010) 13426-13438.

[88] M. Fukuda, C. Moriyama, T. Yamazaki, Y. Imaeda, A. Koga, Quantitative Correlation between Viscosity of Concentrated MAb Solutions and Particle Size Parameters Obtained from Small-Angle X-ray Scattering, Pharmaceutical research, 32 (2015) 3803-3812.

[89] D. Shukla, B.L. Trout, Preferential Interaction Coefficients of Proteins in Aqueous Arginine Solutions and Their Molecular Origins, The Journal of Physical Chemistry B, 115 (2011) 1243-1253.

[90] T. Arakawa, D. Ejima, K. Tsumoto, N. Obeyama, Y. Tanaka, Y. Kita, S.N. Timasheff, Suppression of protein interactions by arginine: A proposed mechanism of the arginine effects, Biophysical Chemistry, $127(2007) 1-8$.

[91] T.P. Hopp, K.R. Woods, Prediction of protein antigenic determinants from amino acid sequences, Proceedings of the National Academy of Sciences, 78 (1981) 3824-3828.

[92] Q.-S. Du, J.-Z. Meng, S.-M. Liao, R.-B. Huang, Energies and physicochemical properties of cation- $\pi$ interactions in biological structures, Journal of Molecular Graphics and Modelling, 34 (2012) 38-45. [93] S.M. Liao, Q.S. Du, J.Z. Meng, Z.W. Pang, R.B. Huang, The multiple roles of histidine in protein interactions, Chem. Cent. J., 7 (2013).

[94] S.Y. Jiang, Z.Q. Cao, Ultralow-Fouling, Functionalizable, and Hydrolyzable Zwitterionic Materials and Their Derivatives for Biological Applications, Adv. Mater., 22 (2010) 920-932.

[95] G. Xie, S.N. Timasheff, The thermodynamic mechanism of protein stabilization by trehalose, Biophysical Chemistry, 64 (1997) 25-43.

[96] T. Arakawa, S.N. Timasheff, Stabilization of protein structure by sugars, Biochemistry, 21 (1982) 6536-6544. 


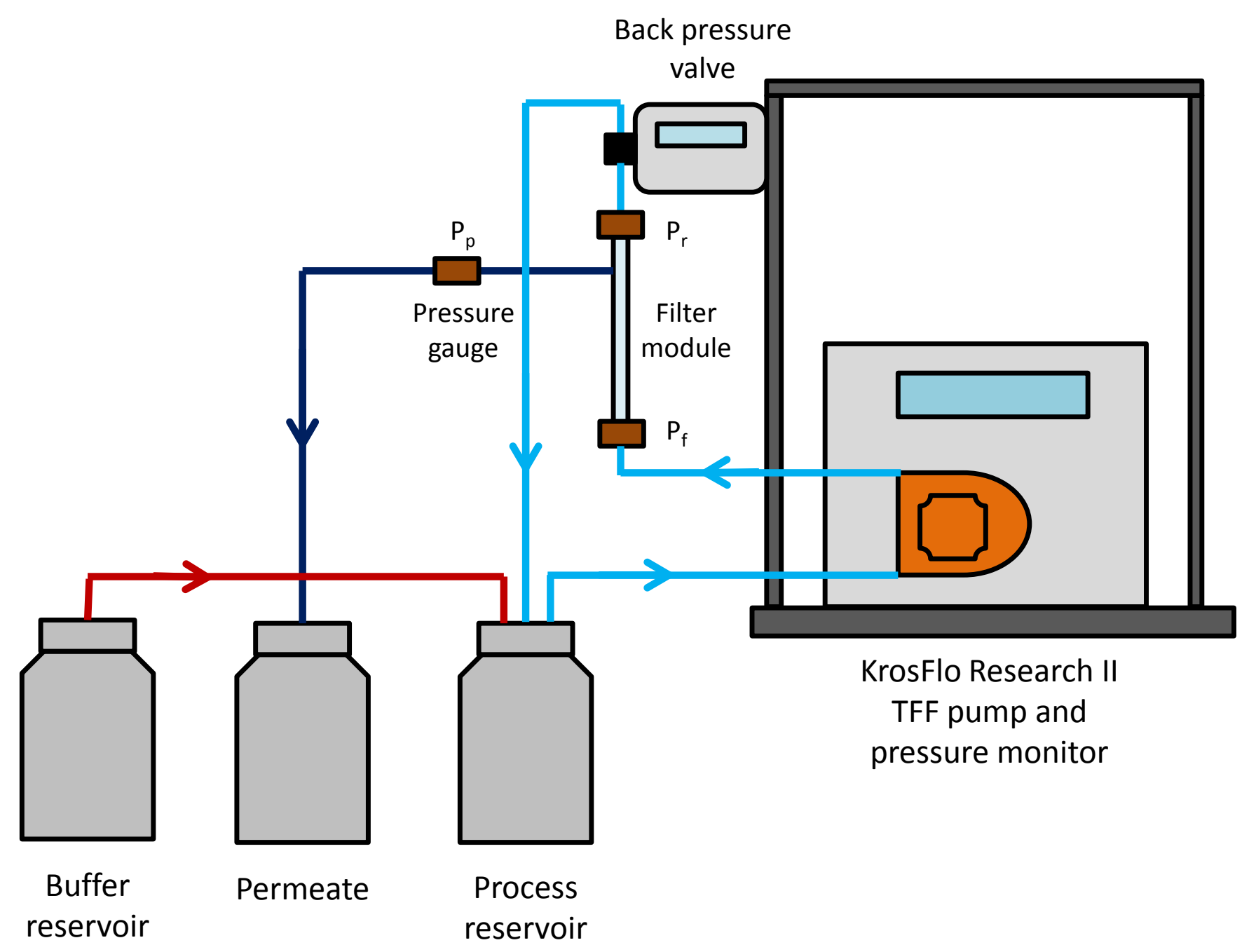




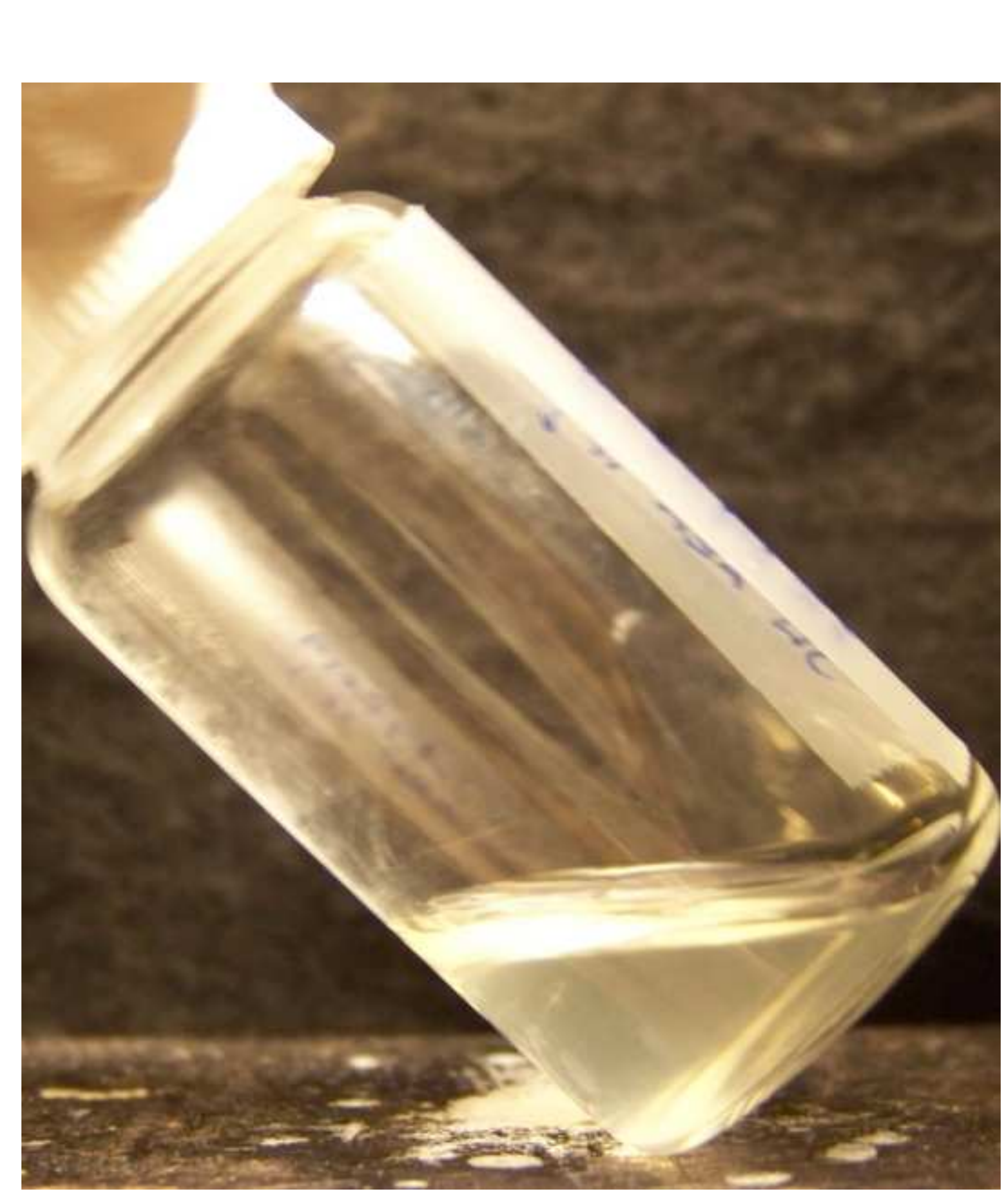

Figure

Figure

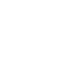

(⿸丆口

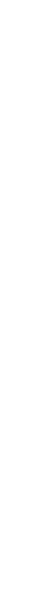

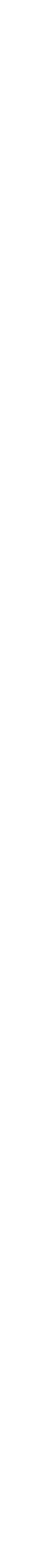

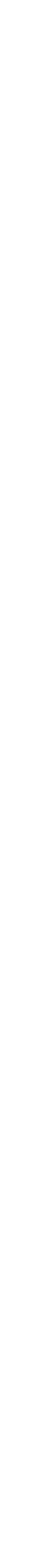




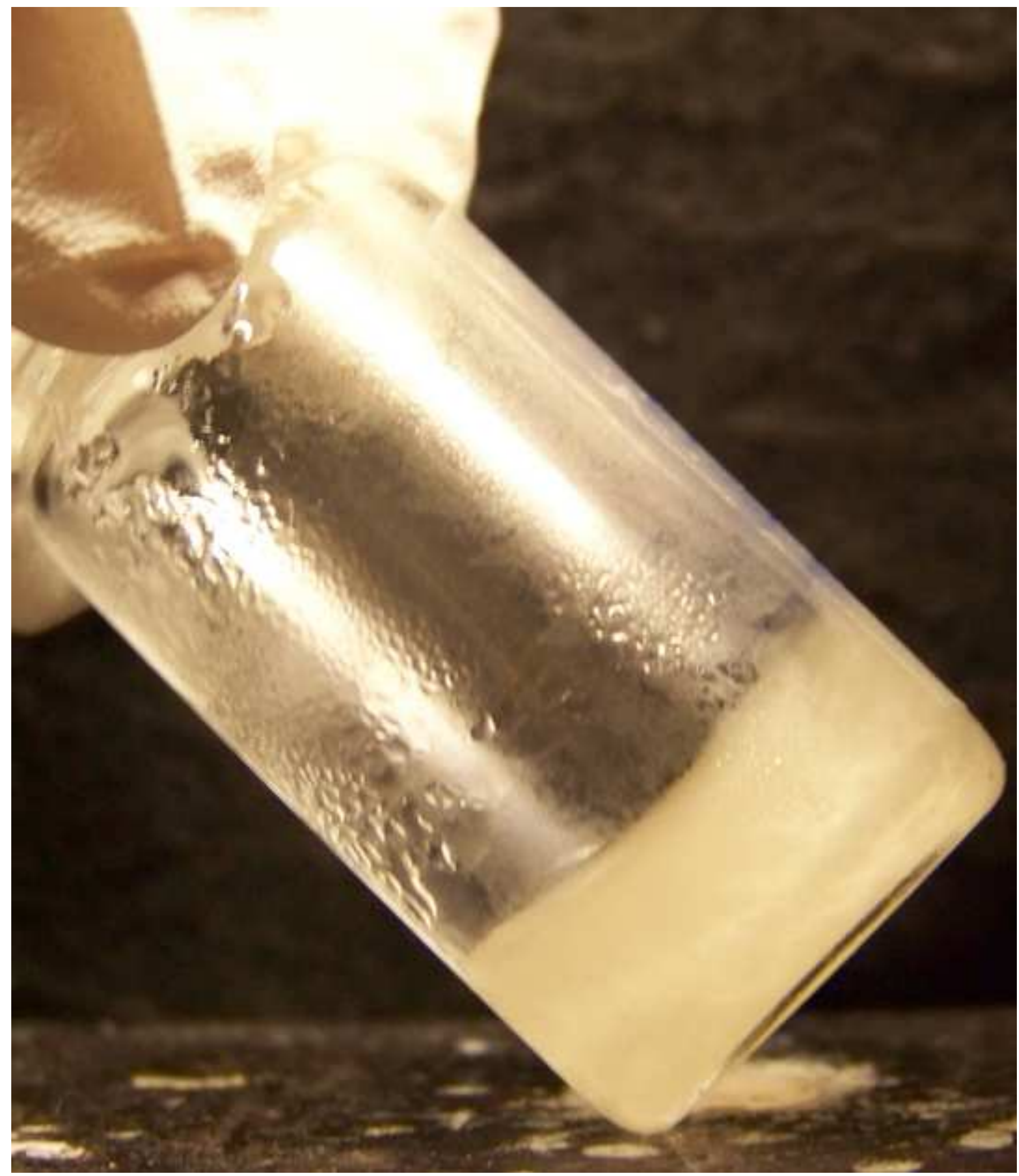

